\title{
Continuous Damping Control for Rollover Prevention with Optimal Distribution Strategy of Damping Force
}

\author{
Xu Zhang ${ }^{1}$, Chuanxue Song ${ }^{1}$, Shixin Song ${ }^{2}$, Jingwei Cao ${ }^{1} \mathbb{B}$, Da Wang ${ }^{1}$, Chunyang Qi ${ }^{1}$, \\ Zhinan Ma ${ }^{3}$ and Feng Xiao ${ }^{1,4, *(D)}$ \\ 1 State Key Laboratory of Automotive Simulation and Control, Jilin University, Changchun 130022, China; \\ xuz19@mails.jlu.edu.cn (X.Z.); scx@jlu.edu.cn (C.S.); caojw18@mails.jlu.edu.cn (J.C.); \\ wangda_gspeed@jlu.edu.cn (D.W.); qicy17@mails.jlu.edu.cn (C.Q.) \\ 2 College of Mechanical and Aerospace Engineering, Jilin University, Changchun 130022, China; \\ songshx202@126.com \\ 3 BAIC Group Off-Road Vehicle Co., Ltd., Beijing 101300, China; mazhinan@beijing-atc.com.cn \\ 4 Taizhou Automobile Power Transmission Research Institute, Jilin University, Taizhou 225322, China \\ * Correspondence: xiaofengjl@jlu.edu.cn
}

Received: 8 September 2020; Accepted: 12 October 2020; Published: 16 October 2020

\begin{abstract}
Vehicle rollover has always been a highly dangerous condition that can cause severe traffic casualties. In this work, a 14-degree-of-freedom vehicle model in MATLAB/Simulink is constructed with the vehicle suspension system dynamics. The validity of the model is verified by comparing with the CarSim model. Then an optimal distribution of damping force strategy with continuous damping control is proposed by combining the traditional lateral load transfer ratio control with optimized equations of suspension damping force. The damping force compensation of the left and right sides is the core of the optimal distribution of damping force strategy. The effectiveness and optimization effect of the optimal distribution of damping force strategy is proved by the simulation results under the fishhook and crosswind tests. The result shows that continuous damping control has evident control effects on vehicle rollover compared with passive suspension. The optimal distribution of the damping force strategy with continuous damping control has a great better performance than traditional continuous damping control, and it provides a certain assistance to vehicle handling stability.
\end{abstract}

Keywords: rollover prevention; continuous damping control; lateral load transfer ratio; optimal distribution of damping force

\section{Introduction}

Vehicle rollover is a very dangerous type of road accident. With the increasing complexity of the traffic environment and the continuous growth of passenger car ownership, traffic accidents have become commonplace. In 2014, the National Highway Traffic Safety Administration (NHTSA) recorded that $18.9 \%$ percent of traffic fatalities were caused by rollovers (7592 of 40,164) [1]. In 2018, these rollovers caused $22.4 \%$ of the total traffic fatalities according to the NHTSA statistics $(8111$ of 32,675) [2]. Although automobile research and design are constantly improving, the fatality rate remains at a very high level. One major reason is that drivers have difficulty predicting the risk of rollover directly. In the event of a rollover, cars are difficult to control due to the great decline of vehicle handling and the fluctuation of the drivers' psychological state. To protect people's lives and to ensure the safety of property, rollovers must be detected as soon as they occur. Moreover, an active anti-rollover control method must be adopted.

One research hotspot in the field of the active safety control of vehicles is predicting the vehicle driving state and determining the real-time state parameters transmitted to prevent vehicle rollover 
accidents [3,4]. In terms of time sequence, two steps can be taken for vehicle rollover prevention: vehicle rollover warning and vehicle rollover prevention action [5].

Many indexes are used to predict a rollover, and they are also used as vehicle rollover warning parameters. The static stability factor (SSF) is the first basic index that shows the inherent tendency of a vehicle to rollover [6]. It was used by Winkler et al. to explain the relationship between vehicle geometry and rollover stability and to describe the anti-rollover performance of vehicles [7]. As one of the indexes for New Car Assessment Program in evaluating vehicle rollover performance, SSF is defined as half of the ratio of the wheel distance to the mass gravity center height. It ignores the dynamic performance of suspension, and its control strategy has limitations in practical application. The dynamic stability factor (DFC) was indicated by Huston and Kelly to solve the problem in which vehicle dynamic information cannot be reflected in SSF [8]. Energy utilization is another index, which uses vehicle kinetic energy compared with the maximum potential energy [9]. Lateral load transfer ratio (LTR), according to the force between the tire and the road surface, is defined as the ratio of the difference between the vertical loads of the left and right wheels and the sum of these loads [10]. It has been widely used because of its simple expression and good portability [11-14]. Phanomchoeng et al. and Ataei et al. indicated that the tire vertical acceleration and other information are required for an index based on LTR, which can simultaneously identify tripped rollover and un-tripped rollover [15]. To improve the prediction ability of traditional LTR, Larish et al. put forward predictive LTR (PLTR) through a theoretical derivation of the linear vehicle dynamics model [16]. The rollover index (RI) is an experience index proposed by Yoon et al., which uses dynamic simulation and has high precision and certain prediction ability [17]. For RI, a large number of experimental data need to be compared and accumulated. An improved algorithm of RI was formulated by Chou and Chu by using the gray model [18], which adds the prediction function of RI [19]. Moreover, Mashadi et al. proposed a method for judging the rollover of wheels after leaving the ground by studying the dynamic characteristics of vehicles with wheels off the ground [20]. To improve the prediction effect, Chen and Peng proposed a strong prediction ability index called time to rollover (TTR) [21]. TTR is defined according to the lateral pressure and roll angle, depending on the state estimation of the linear vehicle model; it can be realized by different algorithms [22]. In addition, Stankiewicz et al. used the concept of zero moment point (ZMP) to predict the rollover risk of vehicles [23]. Ataei et al. proposed a general rollover index for the detection of rollover in both tripped and un-tripped cases in 2019 [24].

When a rollover index is detected as the risk of rollover, the active anti-rollover control is triggered immediately so that the dynamic behavior of the vehicle is restrained to ensure the rollover stability of the vehicle. Anti-rollover has four basic control methods: active steering, active/semi-active suspension, differential braking, and active stabilizer bar [25]. Among these methods, suspension control is the most direct and effective way to control vehicle roll motion [26,27]. Meanwhile, an active stabilizer bar or active/semi-active suspension is often used in suspension systems. The active stabilizer bar can provide a large roll stiffness and can achieve a very good anti-rollover effect [28,29]. It also needs enough installation space. An active and semi-active suspension system is a kind of automobile suspension mechanism that ensures that people in the car have maximum comfort with suitable control strategy [30]. A slow active suspension is used by Westhuizen et al. to change the roll stiffness of the vehicle and avoid un-tripped rollover by reducing the lateral stability of the vehicle [31]. Chu Duanfeng et al. designed the anti-roll control of semi-active suspension and active suspension using a sliding mode algorithm [5]. However, the ideal control effect cannot be obtained by a single method. To guarantee the lateral and yaw stability of the vehicle, chassis integrated control has been increasingly used. Yoon et al. integrated continuous damping control (CDC) and electronic stability control (ESC) to improve vehicle rollover stability [32]. Yoon et al. also established the CDC, ESC, and active front steering (AFS) integrated control method; the three-mode switching control is proposed to make use of the advantages of AFS and ESC [33]. Tchamna et al. integrated ESC and active suspension, which can prevent vehicle rollover by directly controlling suspension travel [34]. 
In the field of automatic driving, many new integrated anti-rollover control methods have also been proposed in recent years [35-37].

This paper includes the following three parts: the vehicle dynamics model and model verification (Part 1), the design of the optimal distribution strategy of the damping force controller (Part 2), and the simulation and result analysis (Part 3).

In Part 1, a 14-degree-of-freedom model, including the longitudinal, lateral, vertical, roll, pitch and yaw direction of vehicle, and rotation and jump of each vehicle wheel, is constructed in MATLAB/Simulink with numerous equations with vehicle suspension system dynamics. The basic parameters of the vehicle are set, and the same parameters are selected for simulation in both MATLAB/Simulink and CarSim. The validity of the model is verified by comparing it with the CarSim model.

In Part 2, an optimal distribution of a damping force strategy with continuous damping control is proposed by combining the traditional lateral load transfer ratio control with the optimized equations of suspension damping force. The damping force compensation of the left and right sides is the core of the optimal distribution of the damping force strategy.

In Part 3, the effectiveness and optimization effect of the optimal distribution of the damping force strategy is proven by the simulation results under the fishhook and crosswind tests. The result shows that continuous damping control has an evident control effect on vehicle rollover compared with passive suspension. The optimal distribution of the damping force strategy with continuous damping control has better performance than the traditional continuous damping control. Moreover, it provides a certain assistance to vehicle handling stability.

\section{Vehicle Dynamics Model and Model Verification}

\subsection{Fourteen-Degree-of-Freedom Vehicle Model}

A 14-degree-of-freedom model was constructed to indicate a nonlinear dynamic vehicle [38]. Numerous sub-models and equations were involved in the whole vehicle, such as the steering model, driving and braking model, wheel rotating model, and tire model by magic formula. Only the equations related to vehicle roll dynamics and suspension dynamics are listed below.

\subsubsection{Vehicle Dynamics Equations}

As shown in Figure 1, the vehicle dynamics equations of an automobile in a horizontal, longitudinal symmetry plane and a transverse symmetry plane passing through a mass center can be written as the following equations:

$$
\begin{gathered}
m_{t}(\dot{u}+q w-r v) \\
=m_{s} h^{\prime}(\dot{q}+p r)+\left(F_{x l 1}+F_{x r 1}+F_{x l 2}+F_{x r 2}\right)-F_{i}-F_{w}-F_{f} \\
m_{t}(\dot{v}+r u-p w)=-m_{s} h^{\prime}(\dot{p}+q r)+\left(F_{y l 1}+F_{y r 1}+F_{y l 2} F_{y r 2}\right) \\
I_{z z} \dot{r}=\left(I_{x x}-I_{y y}\right) p q+L_{1}\left(F_{y l 1}+F_{y r 1}\right)-L_{2}\left(F_{y l 2}+F_{y r 2}\right)+\frac{B_{1}}{2}\left(F_{x l 1}-F_{x r 1}\right) \\
+\frac{B_{2}}{2}\left(F_{x l 2}-F_{x r 2}\right)
\end{gathered}
$$

where $m_{t}$ and $m_{s}$ are the vehicle total and sprung mass, respectively. $u, v$, and $w$ are the longitudinal, lateral, and vertical speed of the vehicle, respectively. $r, p$, and $q$ are the yaw angle rate, roll angle rate, and pitch angle rate of the vehicle body, respectively. $I_{x x}, I_{y y}$, and $I_{z z}$ are the moment inertia of the vehicle around the $\mathrm{X}$-axis, $\mathrm{Y}$-axis, and $\mathrm{Z}$-axis, respectively. In addition, $F_{x i j}$ and $F_{y i j}$ are the longitudinal and lateral force of each wheel, respectively. $L_{j}$ is the longitudinal distance from each axle to the mass center, while $B_{j}$ is the wheel distance of each axle. $h^{\prime}$ is the vertical distance from the mass center to the roll axis. $F_{i}, F_{w}$, and $F_{f}$ are the slope, aerodynamics, and rolling resistance force, respectively. Subscript 
$i(l$ or $r)$ indicates the left and right sides of the wheel, while subscript $j(1$ or 2$)$ indicates the front and rear axles.

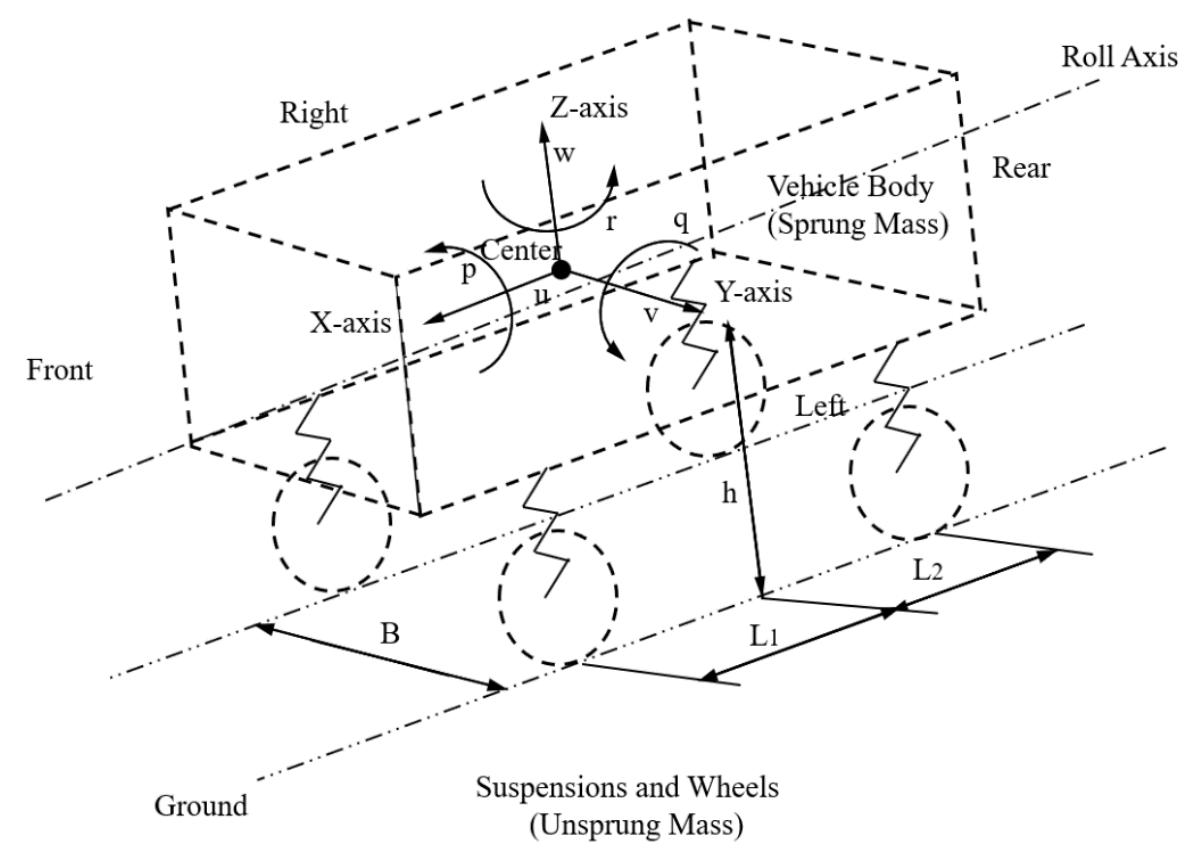

Figure 1. A 14-degree-of-freedom vehicle model (including longitudinal, lateral, vertical, roll, pitch and yaw direction of vehicle, and rotation and jump of each wheel).

\subsubsection{Body Motion Equations}

When the vehicle is moving, the motion of the vehicle body can be regarded as a rigid body. According to rigid body motion theory and angular momentum theory, the mass of a car body in motion satisfies the following differential equations:

Pitch motion equation:

$$
I_{y y s} \dot{q}+\left(I_{x x s}-I_{z z s}\right) p r=-L_{1}\left(\frac{F_{v l 1}}{D_{l 1}}+\frac{F_{v r 1}}{D_{r 1}}\right)+L_{2}\left(\frac{F_{v l 2}}{D_{l 2}}+\frac{F_{v r 2}}{D_{r 2}}\right)+h\left(F_{x l 1}+F_{x r 1}+F_{x r 1}+F_{x r 2}\right)
$$

Roll motion equation:

$$
\begin{gathered}
I_{x x s} \dot{p}+\left(I_{z z s}-I_{y y s}\right) q r \\
=\left(A_{l 1} F_{v l 1}+A_{r 1} F_{v r 1}+A_{l 2} F_{v l 2}+A_{r 2} F_{v r 2}\right)+m_{s} g h^{\prime} \sin \varphi \\
-m_{s} h^{\prime}(\dot{v}+r u-p w) \\
D_{i j}=\frac{a_{i j}+b_{i j}}{b_{i j}} \\
A_{i j}=\left\{\begin{array}{cl}
-n_{l j}+\left(n_{l j}-b_{l j}\right) \frac{a_{l j}}{a_{l l}+b_{l j},} & \text { on the left wheel } \\
n_{r j}-\left(n_{r j}-b_{r j}\right) \frac{a_{r j}+b_{r j}}{a_{r j}} & \text { on the right wheel }
\end{array}\right.
\end{gathered}
$$

where $h$ is the height of the mass center. $F_{v i j}$ is the vertical force of each wheel. $I_{x x s}, I_{y y s}$, and $I_{z z s}$ are the moment inertia of the vehicle sprung mass around the $\mathrm{X}$-axis, Y-axis, and Z-axis, respectively. $g$ is the acceleration of gravity. $A_{i j}, D_{i j}, a_{i j}, b_{i j}$, and $n_{i j}$ are the geometry parameters related to the suspension connection structure of each wheel. $\varphi$ is the roll angle of the vehicle. 


\subsubsection{Suspension Motion Equations}

Suspension model is shown in Figure 2. As shown in Figures 1 and 2, the body and wheel vertical motion equations are as follows:

$$
\begin{gathered}
m_{s}(\dot{w}+p v-q u)=\frac{F_{v l 1}}{D_{l 1}}+\frac{F_{v r 1}}{D_{r 1}}+\frac{F_{v l 2}}{D_{l 2}}+\frac{F_{v r 2}}{D_{r 2}} \\
\left\{\begin{array}{c}
m_{u l 1} \dot{w}_{u l 1}=K_{u l 1}\left(Z_{r l 1}-Z_{u l 1}\right)+C_{u l 1}\left(w_{r l 1}-w_{u l 1}\right)-\frac{F_{v l 1}}{D_{l 1}} \\
m_{u l 2} \dot{w}_{u l 2}=K_{u l 2}\left(Z_{r l 2}-Z_{u l 2}\right)+C_{u l 2}\left(w_{r l 2}-w_{u l 2}\right)-\frac{F_{v l 2}}{D_{l 2}} \\
m_{u r 1} \dot{w}_{u r 1}=K_{u r 1}\left(Z_{r r 1}-Z_{u r 1}\right)+C_{u r 1}\left(w_{r r 1}-w_{u r 1}\right)-\frac{F_{v r 1}}{D_{r 1}} \\
m_{u r 2} \dot{w}_{u r 2}=K_{u r 2}\left(Z_{r r 2}-Z_{u r 2}\right)+C_{u r 2}\left(w_{r r 2}-w_{u r 2}\right)-\frac{F_{v r 2}}{D_{r 2}}
\end{array}\right.
\end{gathered}
$$

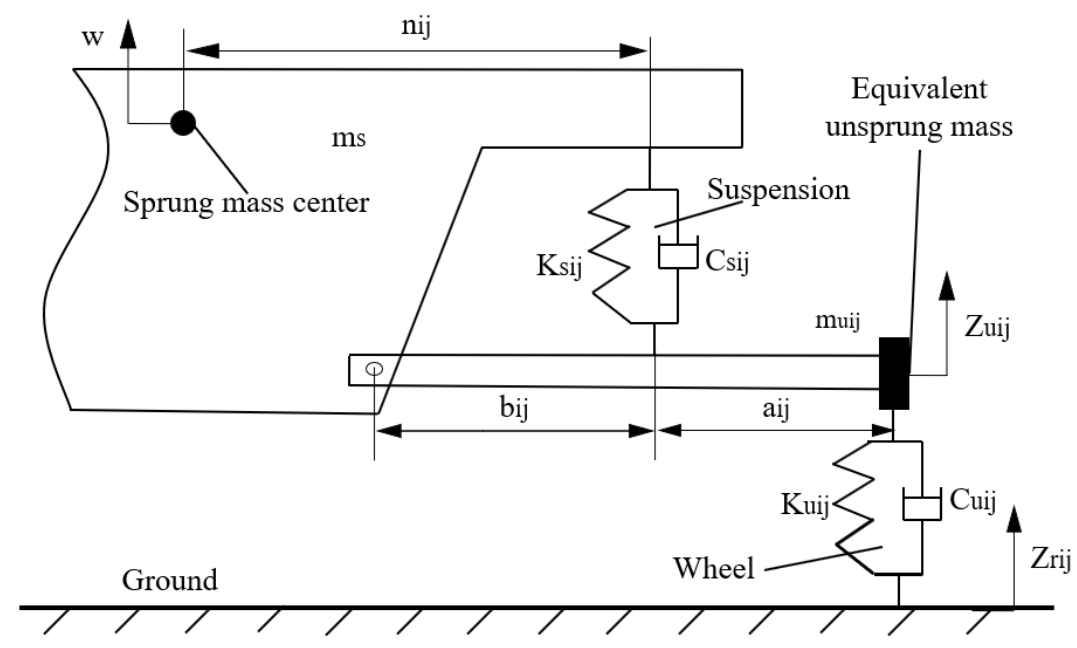

Figure 2. Suspension model. The unsprung mass of the suspension components and the wheels is replaced by an equivalent unsprung mass in this model.

The force on the suspension by each wheel can be expressed by the following equations:

$$
\begin{aligned}
& F_{v l 1}=K_{s l 1}\left(Z_{u l 1}-Z_{s}+L_{1} \sin \theta+n_{l 1} \sin \varphi\right)+C_{s l 1}\left(Z_{u l 1}^{\cdot}-w+L_{1} q \cos \theta+n_{l 1} p \cos \varphi\right) \\
& F_{v l 2}=K_{s l 2}\left(Z_{u l 2}-Z_{s}-L_{2} \sin \theta+n_{l 2} \sin \varphi\right)+C_{s l 2}\left(Z_{u l 2}^{\cdot}-w-L_{2} q \cos \theta+n_{l 2} p \cos \varphi\right) \\
& F_{v r 1}=K_{s r 1}\left(Z_{u r 1}-Z_{s}+L_{1} \sin \theta-n_{r 1} \sin \varphi\right)+C_{s r 1}\left(Z_{u r 1}-w+L_{1} q \cos \theta-n_{r 1} p \cos \varphi\right) \\
& F_{v r 2}=K_{s r 2}\left(Z_{u r 2}-Z_{s}-L_{2} \sin \theta-n_{r 2} \sin \varphi\right)+C_{s r 2}\left(Z_{u r 2}-w-L_{2} q \cos \theta-n_{r 2} p \cos \varphi\right)
\end{aligned}
$$

where $m_{u}$ is the unsprung mass, and $\theta$ is the pitch angle of the vehicle. $K_{s i j}$ and $K_{u i j}$ are the stiffness coefficients of the spring and the wheel, respectively. $C_{s i j}$ and $C_{u i j}$ are the damping coefficients of the shock absorber and the wheel, respectively. $Z_{\text {sij }}$ and $Z_{u i j}$ are the sprung and unsprung mass displacement of each wheel. $Z_{r i j}$ is the road roughness of each wheel.

\subsection{Model Verfication}

The vehicle model is constructed in MATLAB/Simulink (abbreviated as Simulink below). The graphical simulation model generated by Simulink is mainly based on the dynamic equation of the system built by users. Compared with the multi-body dynamic model, the biggest advantage of the Simulink model is that the combination of the model and the control system is more convenient. Moreover, the performance of the vehicle before and after the control can be compared and studied intuitively. 
Given the high simulation accuracy of the software CarSim, the CarSim model is regarded as the actual vehicle in the model verification. The model in Simulink is verified by inputting the same vehicle parameters under the same sine input of the steering wheel both in Simulink and CarSim as shown in Table 1. The comparison results are shown in Figure 3 and Table 2 below.

Table 1. Main parameters of vehicle model.

\begin{tabular}{ccc}
\hline Vehicle Parameters & Value & Unit \\
\hline $\mathrm{m}_{\mathrm{t}}$ & 900 & $\mathrm{~kg}$ \\
$\mathrm{~m}_{\mathrm{s}}$ & 700 & $\mathrm{~kg}$ \\
$\mathrm{I}_{\mathrm{xx}}$ & 268 & $\mathrm{~kg} \cdot \mathrm{m}^{2}$ \\
$\mathrm{I}_{\mathrm{yy}}$ & 708 & $\mathrm{~kg} \cdot \mathrm{m}^{2}$ \\
$\mathrm{I}_{\mathrm{zz}}$ & 708 & $\mathrm{~kg} \cdot \mathrm{m}^{2}$ \\
$\mathrm{~h}$ & 700 & $\mathrm{~mm}$ \\
$\mathrm{~B}_{1}$ & 1469 & $\mathrm{~mm}$ \\
$\mathrm{~B}_{2}$ & 1430 & $\mathrm{~mm}$ \\
$\mathrm{~L}_{1}$ & 970 & $\mathrm{~mm}$ \\
$\mathrm{~L}_{2}$ & 903 & $\mathrm{~mm}$ \\
$\mathrm{~g}$ & 9.8 & $\mathrm{~m} / \mathrm{s}^{2}$ \\
$\mathrm{~K}_{\mathrm{s} 11} / \mathrm{K}_{\mathrm{sr} 1}$ & 14 & $\mathrm{~N} / \mathrm{mm}$ \\
$\mathrm{K}_{\mathrm{s} 12} / \mathrm{K}_{\mathrm{sr} 2}$ & 18 & $\mathrm{~N} / \mathrm{mm}$ \\
\hline
\end{tabular}

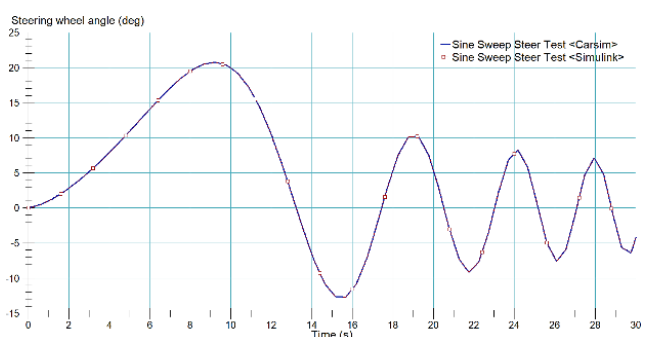

(a)

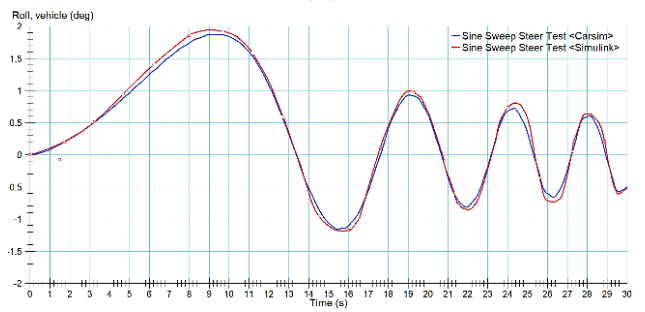

(c)

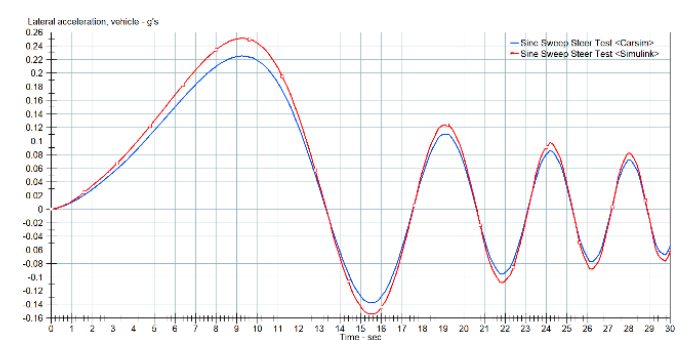

(b)

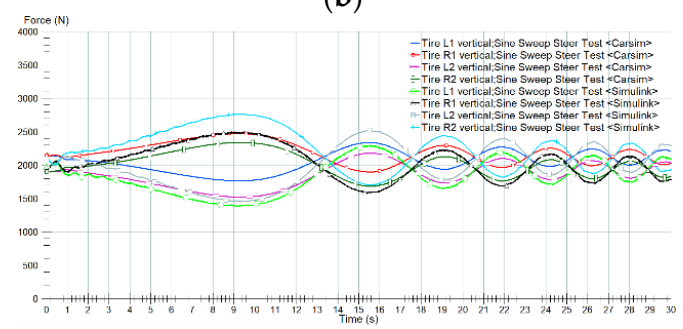

(d)

Figure 3. Model comparison results (red solid line with little square is the result of the Simulink simulation; blue solid line is the result of the CarSim simulation except in (d)). (a) is the input steering angle; (b) is the comparison of the lateral acceleration; (c) is the comparison of the roll angle; (d) is the comparison of the vertical force of each wheel.

Table 2. Main results of comparison.

\begin{tabular}{ccccc}
\hline \multicolumn{2}{c}{ Test Results (Unit) } & CarSim & Simulink & Percentage Point $^{\mathbf{1}^{2}}$ \\
\hline \multirow{3}{*}{ Roll angle $(\mathrm{deg})$} & maximum & 1.882669 & 1.9110172 & $1.50 \%$ \\
& minimum & -1.140343 & -1.149754 & $0.83 \%$ \\
& average & 0.3543169 & 0.3560246 & $0.48 \%$ \\
\multirow{2}{*}{ Lateral acceleration $\left(g^{\prime}\right.$ s) $)$} & maximum & 0.2252319 & 0.2512166 & $11.5 \%$ \\
& minimum & -0.1377398 & -0.1543274 & $12.0 \%$ \\
& average & 0.04496558 & 0.04642835 & $3.25 \%$ \\
\hline
\end{tabular}

\footnotetext{
${ }^{1}$ Percentage point $=(($ Simulink $)-($ CarSim $)) /($ CarSim $) \times 100 \%$.
} 
Despite the relatively small differences (related to the number of degrees of freedom and other physical parameters, such as tire stiffness and damping), the change trend of the model is correct, and the simulation parameters related to vehicle roll are very accurate (such as roll angle). The 14-degree-of-freedom model in Simulink has good simulation accuracy and can thus be used for simulation.

\section{Design of Optimal Distribution Strategy of Damping Force Controller}

\subsection{Lateral Load Transfer Ratio}

The lateral load transfer rate (LTR) is the mainstream rollover evaluation index, and it is commonly used in the rollover control field [39]. When the vehicle is rolling, its LTR can be expressed by vertical force as the following equation, as shown in Figure 4 [12]:

$$
L T R=\frac{F_{z l}-F_{z r}}{F_{z l}+F_{z r}}
$$

where $F_{z l}, F_{z r}$ are the left and right vertical forces of sprung mass, which can be expressed as

$$
\left\{\begin{array}{c}
F_{z l}=F_{z l 1}+F_{z l 2}=\frac{F_{v l 1}}{D_{l 1}}+\frac{F_{v l 2}}{D_{l 2}} \\
F_{z r}=F_{z r 1}+F_{z r 2}=\frac{F_{v r 1}}{D_{r 1}}+\frac{F_{v r 2}}{D_{r 2}}
\end{array}\right.
$$

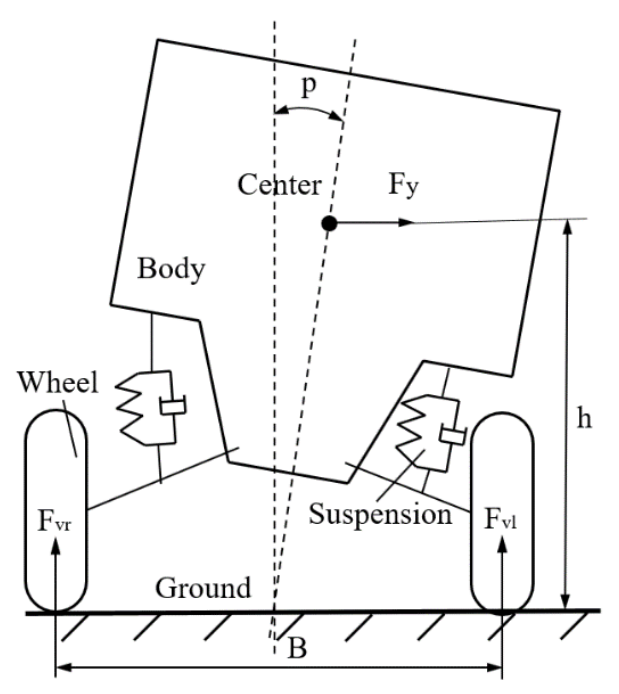

Figure 4. Vehicle rollover diagram (front view).

It can be seen from Equation (14) that when the vehicle runs in a straight line without steering wheel input, the vehicle has no load transfer and the LTR is 0 . When the input of the steering wheel increases gradually, the vehicle body will roll due to the effect of suspension and the vertical forces of outside wheels will gradually increase. Assuming that the lateral acceleration is constant, the vertical forces of the inside wheel will decrease correspondingly, and the LTR value will gradually increase. When the rollover critical moment is reached, the vertical forces of the inside wheels inside will be 0 . The wheels on another side carry all the mass of the vehicle, and the LTR reaches the maximum value of +1 or the minimum value of -1 . At this time, if the input of steering wheel angle continues to increase, the rollover accident will occur. Therefore, the value range of LTR is $[-1,+1]$. 


\subsection{Optimal Distribution Strategy of Damping Force}

According to the relevant theories of LTR, the ideal anti-rollover damping moment can be expressed as

$$
M_{x D n-r o l l}=\frac{B_{1}}{2}\left(F_{D l 1}-F_{D r 1}\right)+\frac{B_{2}}{2}\left(F_{D l 2}-F_{D r 2}\right)=-F_{y} h=-M_{x}
$$

where $M_{x D n \text {-roll }}$ is the anti-rollover moment provided by the damping force. $F_{D i j}$ is the damping force of each wheel. $M_{x}$ is the roll moment around the X-axis, which can be solved by the vehicle dynamic model constructed by Equations (1)-(8).

Considering the theory of semi-active suspension, the power of the shock absorber must be positive. CDC can only convert mechanical energy into thermal energy without the injection of external energy, that is,

$$
P_{\text {Dij-roll }}=\left\{\begin{array}{r}
F_{D i j}\left(w-\dot{Z_{u i j}}\right)=C_{n i j-r o l l} w\left(w-Z_{u i j}\right), w\left(w-Z_{u i j}\right)>0 \\
0, w\left(w-Z_{u i j}\right) \leq 0
\end{array}\right.
$$

$$
F_{D i j} \operatorname{Sign}\left(Z_{D i j}\right) \geq 0
$$

where the function $\operatorname{Sign}(x)$ is described as:

$$
\begin{gathered}
\operatorname{Sign}(x)=\left\{\begin{array}{r}
1, x>0 \\
0, x=0 \\
-1, x<0
\end{array}\right. \\
Z_{D i j}=w-Z_{u i j}
\end{gathered}
$$

where $Z_{D i j}$ is the displacement of the shock absorber of each wheel; $x$ is a variable; $P_{D-\text { roll }}$ is the power of anti-rollover shock absorber. $C_{n-\text { roll }}$ is the damping coefficient of the anti-rollover shock absorber.

In this paper, the damping force is a free variable to be distributed. Only when the vertical forces are optimized, the distribution result of vertical forces is better, but the damping force are greatly different. Large suspension dynamic displacements caused by damping force control will affect vehicle stability. Thus, the vertical load difference of each wheel between the dynamic and static condition should not be too large to avoid the large wheel dynamic load caused by the semi-active suspension control, which worsens the vehicle handling stability [40,41]. The optimized performance index of the vertical dynamic load is defined as:

$$
J_{v d}=t_{l 1}\left(\frac{F_{v l 10}}{F_{v l 1}}\right)^{2}+t_{l 2}\left(\frac{F_{v l 2 o}}{F_{v l 2}}\right)^{2}+t_{r 1}\left(\frac{F_{v r 10}}{F_{v r 1}}\right)^{2}+t_{r 2}\left(\frac{F_{v r 20}}{F_{v r 2}}\right)^{2}
$$

where $t$ is the weighting factor; $F_{v i j o}$ is the static vertical force of each wheel.

The constrained optimization problem can be defined as:

$$
\min _{F_{D i j}} J_{v d}\left(M_{x D n-r o l l}, Z_{D i j}^{\cdot}, F_{D i j}\right)
$$

Equation (19) can be simplified by using the defined variables, $\alpha_{i j}$ and $\beta_{i j}$, as

$$
\begin{gathered}
J_{v d}=\frac{\alpha_{l 1}}{\left(F_{D l 1}+\beta_{l 1}\right)^{2}}+\frac{\alpha_{l 2}}{\left(F_{D l 2}+\beta_{l 2}\right)^{2}}+\frac{\alpha_{r 1}}{\left(F_{D r 1}+\beta_{r 1}\right)^{2}}+\frac{\alpha_{r 2}}{\left(F_{D r 2}+\beta_{r 2}\right)^{2}} \\
\alpha_{i j}=t F_{v i j o}^{2} \\
\beta_{i j}=F_{v i j}-F_{D i j}
\end{gathered}
$$


The Lagrange multiplier method is used to solve the optimization problem in Equation (22). The optimization objective function considering the constraints of Equations (16) and (18) is constructed as

$$
\begin{aligned}
L_{\text {multiplier }}=J_{v d}+ & \gamma\left(M_{x D n-\text { roll }}-\frac{B_{1}}{2}\left(F_{D l 1}-F_{D r 1}\right)-\frac{B_{2}}{2}\left(F_{D l 2}-F_{D r 2}\right)\right) \\
& -\sum \lambda_{i j}\left(F_{D i j} \operatorname{Sign}\left(Z_{D i j}\right)-\varepsilon_{i j}{ }^{2}\right)
\end{aligned}
$$

where $\gamma$ and $\varepsilon_{i j}$ are arbitrary real numbers; $\lambda_{i j}$ represent nonnegative real numbers. When the objective variable, $J_{v d}$, takes the extreme value, the partial derivative of each parameter is equal to 0 . The partial differential equation can be written as

$$
\left\{\begin{array}{c}
\frac{\partial L_{\text {multiplier }}}{\partial F_{D 11}}=\frac{-2 \alpha_{l 1}}{\left(F_{D l 1}+\beta_{l 1}\right)^{3}}-\gamma-F_{D l 1} \operatorname{Sign}\left(Z_{D l 1}\right)=0 \\
\frac{\partial L_{\text {multiplier }}}{\partial F_{D l 2}}=\frac{-2 \alpha_{l 2}}{\left(F_{D l 2}+\beta_{l 2}\right)^{3}}-\gamma-F_{D l 2} \operatorname{Sign}\left(Z_{D l 2}\right)=0 \\
\frac{\partial L_{\text {multiplier }}}{\partial F_{D r 1}}=\frac{-2 \alpha_{r 1}}{\left(F_{D r 1}+\beta_{r 1}\right)^{3}}+\gamma-F_{D r 1} \operatorname{Sign}\left(Z_{D r 1}\right)=0 \\
\frac{\partial L_{\text {multiplier }}}{\partial F_{D r 2}}=\frac{-2 \alpha_{r 2}}{\left(F_{D r 2}+\beta_{r 2}\right)^{3}}+\gamma-F_{D r 2} \operatorname{Sign}\left(Z_{D r 2}\right)=0 \\
\frac{\partial L_{\text {multiplier }}}{\partial F_{\lambda i j}}=-F_{D i j} \operatorname{Sign}\left(Z_{D i j}\right)=0 \\
\frac{\partial L_{\text {multiplier }}}{\partial F_{\varepsilon i j}}=2 \lambda_{i j} \varepsilon_{i j}=0
\end{array}\right.
$$

In one solution, all $\varepsilon_{i j}$ values that are equal to 0 are excluded because the variable leads to $F_{d i j}=0$, thus conflicting with semi-active control theory. Another solution in which all $\lambda_{i j}$ are 0 is as follows:

$$
\begin{aligned}
& \gamma=\frac{-2 \alpha_{l j}}{\left(F_{d l j}+\beta_{l j}\right)^{3}} \\
& \gamma=\frac{2 \alpha_{r j}}{\left(F_{d r j}+\beta_{r j}\right)^{3}}
\end{aligned}
$$

Equations (29) and (30) may not be able to solve for $\gamma$. Instead, the solution should be

$$
\begin{cases}\lambda_{l j}=0, & \varepsilon_{r j}=0 \\ \lambda_{r j}=0, & \varepsilon_{l j}=0\end{cases}
$$

For the un-tripped rollover investigated in this study, the movement of the left and right sides of the vehicle suspension is always on the contrary, and the damping force on the left and right sides of the suspension is always reversed. The front and rear wheel distance is usually the same or similar, supposing $B=B_{1}$ because the wheel distance should be determined by the outermost wheel in the anti-rollover control [42]. The range of feasible solutions is shown in Figure 5. The theoretical extreme value of the performance index $J_{v d}$ exists only when the damping force of the shock absorber is in the range of the feasible solution shown in Figure 5. In addition, the damping force of the shock absorber may be distributed in quadrants I and III. However, for the un-tripped rollover investigated in this research, the damping force is distributed in quadrants II and IV. The constraint equation of Equation (19) can be written as

$$
\left\{\begin{array}{l}
F_{D l j} \operatorname{Sign}(\dot{\varphi}) \leq 0 \\
F_{D r j} \operatorname{Sign}(\dot{\varphi}) \geq 0
\end{array}\right.
$$




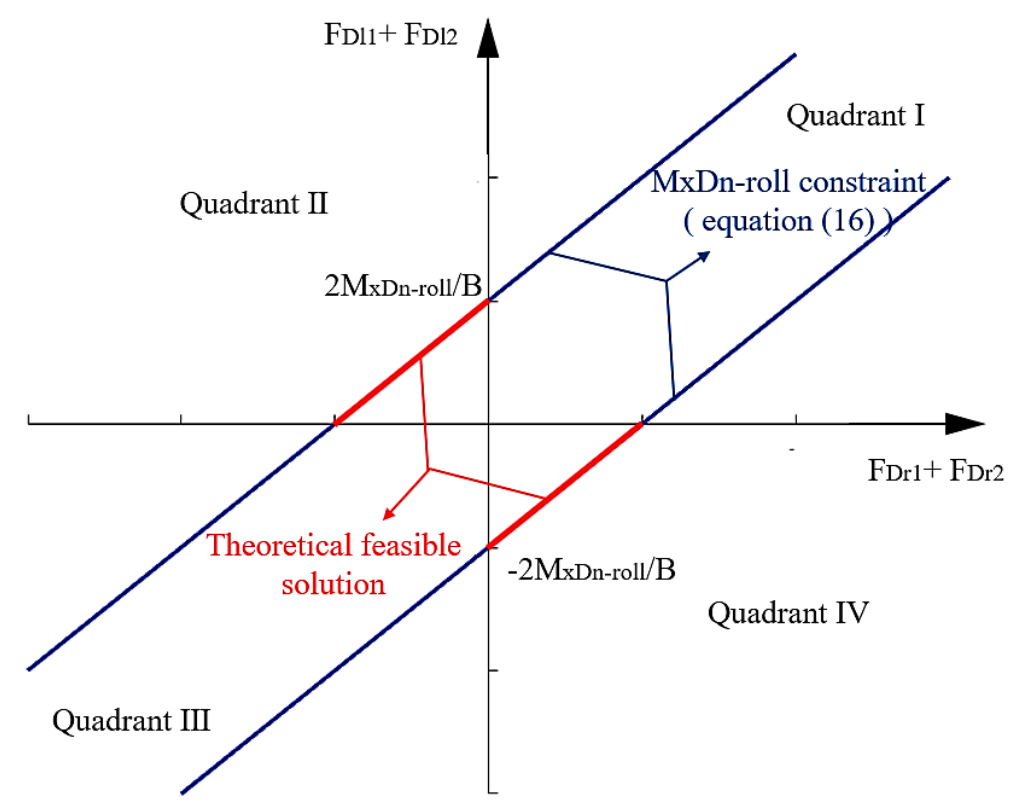

Figure 5. Feasible region of optimal distribution of damping force.

When $\lambda_{r j}=0$, Equations (29) and (31) are substituted into Equation (27):

$$
\frac{\partial L_{\text {multiplier }}}{\partial F_{D l j}}=\frac{-2 \alpha_{l j}}{\left(F_{D l j}+\beta_{l j}\right)^{3}}+\frac{-2 \alpha_{r j}}{\left(F_{D r j}+\beta_{r j}\right)^{3}}+F_{D l j} \operatorname{Sign}(\dot{\varphi})=0
$$

When $\lambda_{r j}$ and $\alpha_{r j}$ are not negative, then $\dot{\varphi}>0$. By the same token, when $\lambda_{l j}=0$, then $\dot{\varphi}<0$. Substituting Equations (28) and (31) into Equation (27):

$$
\frac{\partial L_{\text {multiplier }}}{\partial F_{D r j}}=\frac{-2 \alpha_{r j}}{\left(F_{D r j}+\beta_{r j}\right)^{3}}+\frac{-2 \alpha_{l j}}{\left(F_{D l j}+\beta_{l j}\right)^{3}}+F_{D r j} \operatorname{Sign}(\dot{\varphi})=0
$$

The theoretical solution of the optimization problem in Equation (22) can be expressed as

$$
\left\{\begin{array}{c}
F_{D l j-t}=\frac{-\frac{2 \sqrt[3]{a_{l j}}}{B} M_{x D n-\text { roll }}+\sqrt[3]{\alpha_{l j}} \sum \beta_{l j}-\beta_{l j} \sum \sqrt[3]{\alpha_{l j}}}{\sum \sqrt[3]{a_{l j}}}\left[\frac{1-\operatorname{Sign}\left(M_{x D n-\text { roll }}\right)}{2}\right] \\
F_{D r j-t}=\frac{-\frac{2 \sqrt[3]{a_{r j}}}{B} M_{x D n-\text { roll }}+\sqrt[3]{\alpha_{r j}} \sum \beta_{r j}-\beta_{r j} \sum \sqrt[3]{\alpha_{r j}}}{\sum \sqrt[3]{\alpha_{r j}}}\left[\frac{1+\operatorname{Sign}\left(M_{x D n-\text {-roll }}\right)}{2}\right]
\end{array}\right.
$$

Considering the limitation of the CDC shock absorber, the damper on the other side needs to output a certain compensation damping force when the theoretical solution exceeds the shock absorber limitation. Such force needs to meet or approach the constraint equation of Equation (16) as much as possible to ensure the rollover stability of the vehicle. The limitation characteristics of CDC is indicated as follows:

$$
\operatorname{sat}\left(F_{D i j}\right)=\left\{\begin{array}{l}
F_{D \text { min }},\left|F_{D i j}\right|<\left|F_{D \text { min }}\right| \\
F_{D i j},\left|F_{D \text { min }}\right|<\left|F_{D i j}\right|<\left|F_{D \text { min }}\right|<\left|F_{D \max }\right| \\
F_{D \text { max }},\left|F_{D \text { max }}\right|<\left|F_{D i j}\right|
\end{array}\right.
$$

where $F_{D \min }$ and $F_{D \max }$ are the lower and upper limits of the CDC shock absorber, they can be shown in Figure 6. 


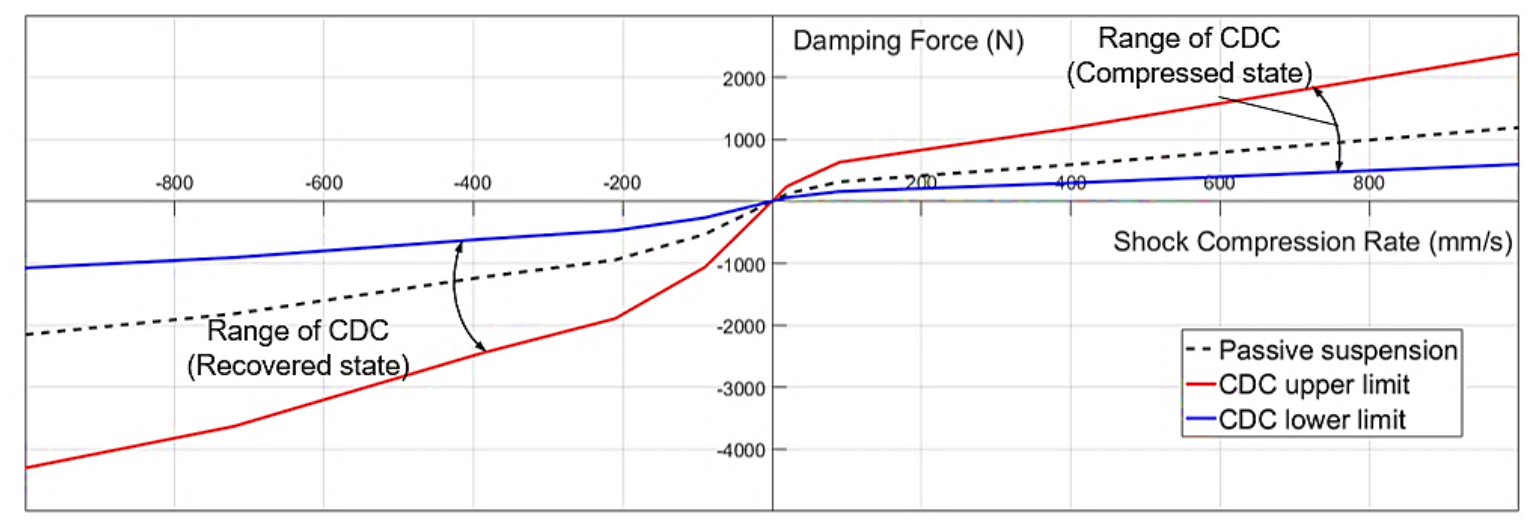

Figure 6. Range of variation of continuous damping control (CDC) damping force.

When the theoretical solution of Equation (34) does not meet the condition of Equation (16), the compensation damping force of the other shock absorber is optimally distributed according to the performance index of Equation (23). The expected damping force considering the shock absorber limit and rollover stability constraints is obtained as follows:

$$
\left\{\begin{array}{c}
F_{D l j-d}=s a t\left\{\frac{-\frac{2 \sqrt[3]{a_{l j}}}{B} M_{x D n-r o l l}+\sqrt[3]{\alpha_{l j}} \sum \beta_{l j}-\beta_{l j} \sum \sqrt[3]{\alpha_{l j}}}{\sum \sqrt[3]{\alpha_{l j}}}\left[\frac{1-\operatorname{Sign}\left(M_{x D n-\text { roll }}\right)}{2}\right]\right\} \\
F_{D r j-d}=\operatorname{sat}\left\{\frac{-\frac{2 \sqrt[3]{\alpha_{r j}}}{B} M_{x D n-\text { roll }}+\sqrt[3]{\alpha_{r j}} \sum \beta_{r j}-\beta_{r j} \sum \sqrt[3]{\alpha_{r j}}}{\sum \sqrt[3]{\alpha_{r j}}}\left[\frac{1+\operatorname{Sign}\left(M_{x D n-\text { roll }}\right)}{2}\right]\right\}
\end{array}\right.
$$

When the expected resistance force is not within the regulation range, the saturation constraint of the shock absorber should be considered and compensated by the shock absorber on the other side. This condition meets the expected moment constraint of anti-rollover preferentially. The distribution of the CDC damping force is optimized, and it effectively avoids the problem regarding the optimization of online solving constraints. The real-time performance of the control algorithm is improved.

\section{Simulation and Result Analysis}

The simulation analysis was carried out in MATLAB/Simulink. The passive suspension and traditional CDC LTR damping on/off control (abbreviated as CDC-LTR) were compared with the CDC optimal distribution damping force strategy (abbreviated as CDC-ODDF) to illustrate the optimization effect. The CDC-LTR to prevent rollover simply sets the absolute threshold value of LTR parameters. When the threshold is reached, the anti-roll control is adopted for CDC suspension. Given that this research mainly focuses on tripped rollover while driving a vehicle, ESC differential braking and other methods of stability control are removed to highlight the control effect of a single CDC on rollover.

For tripped rollover, the lateral force is the main source of the roll force. The lateral force may be caused by the turning of the vehicle itself in the driving process, or it may be caused by the larger lateral wind during the driving process. Therefore, the following is divided into two conditions for stability testing simulation analysis: fishhook and crosswind.

The real vehicle selected for the funding project is an A0 class high-centroid vehicle. Although it has a high centroid, its mass is not large. Moreover, it is more prone to sideslip rather than rollover when that vehicle has no ESC system while driving. Therefore, the selection of its parameters is the critical condition obtained by repeated simulation, which can show the effect of vehicle control under a limited state. 


\subsection{Fishhook Test}

The basic parameters of the fishhook test simulation analysis are shown in Table 3.

Table 3. Main parameters of fishhook test.

\begin{tabular}{ccc}
\hline Test Parameters & Value & Unit \\
\hline Longitude target speed & 80 & $\mathrm{~km} / \mathrm{h}$ \\
Friction coefficient & 0.85 & - \\
Steer input angle peak value & 294 & $\mathrm{deg}$ \\
Simulation time & 20 & second \\
Road condition & straight & - \\
|Threshold of CDC-LTR control| & 0.9 & - \\
\hline CDC-LTR, continuous damping control-lateral load transfer ratio.
\end{tabular}

The results of the fishhook test simulation are shown in Figure 7.

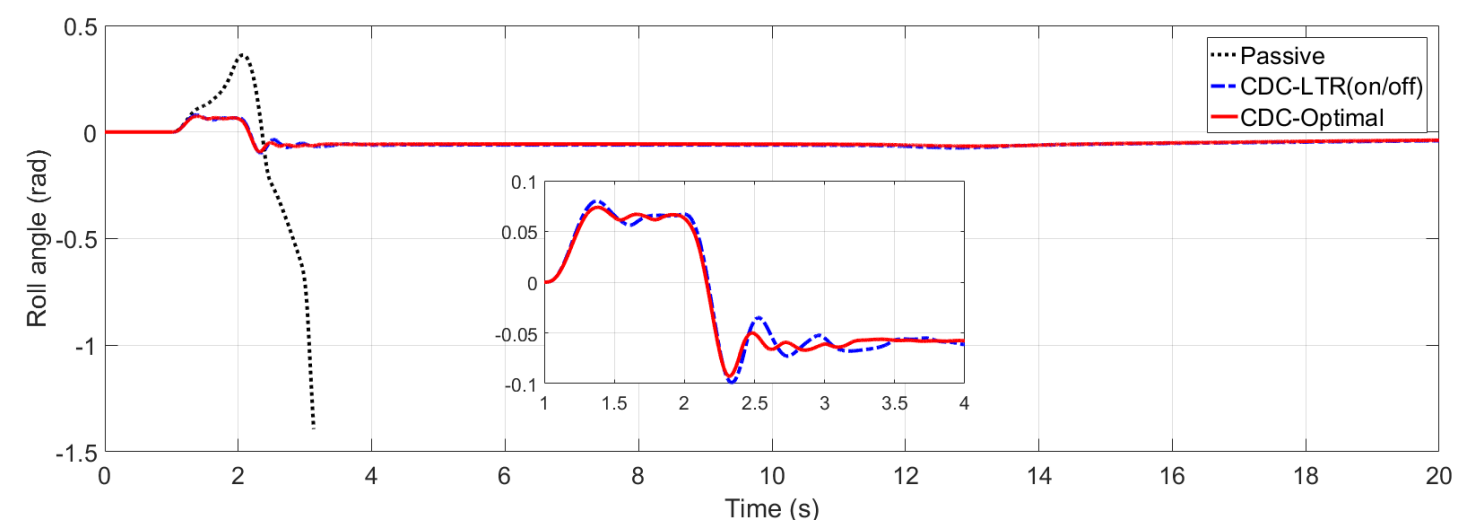

(a)

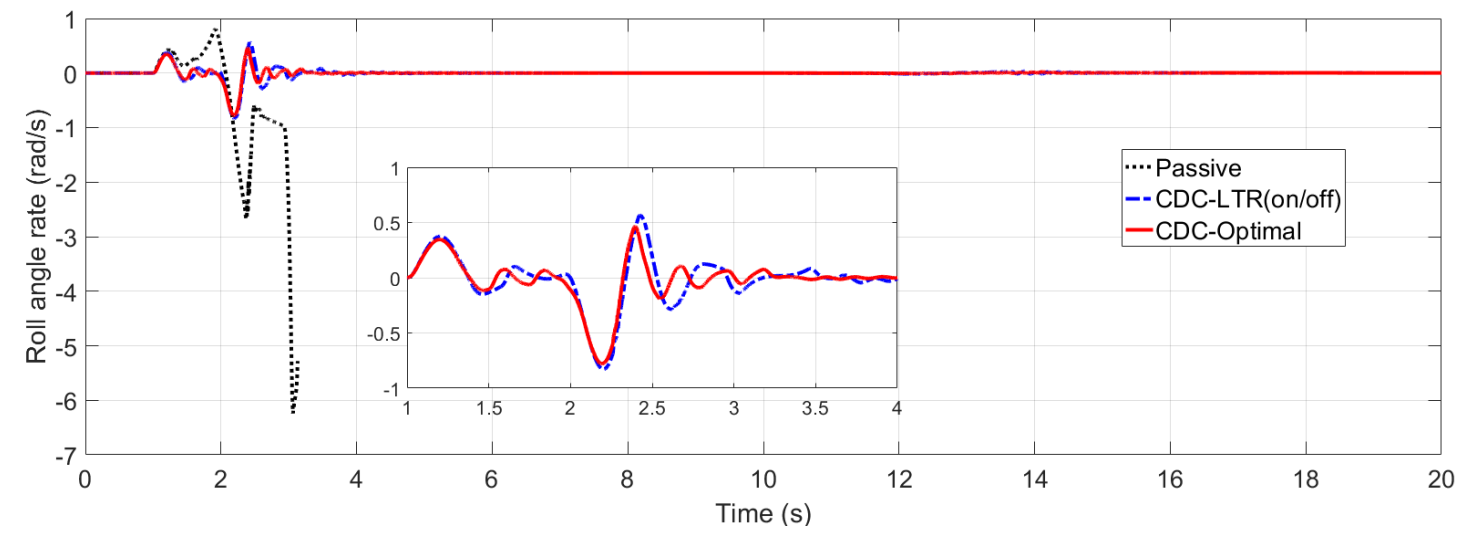

(b)

Figure 7. Cont. 


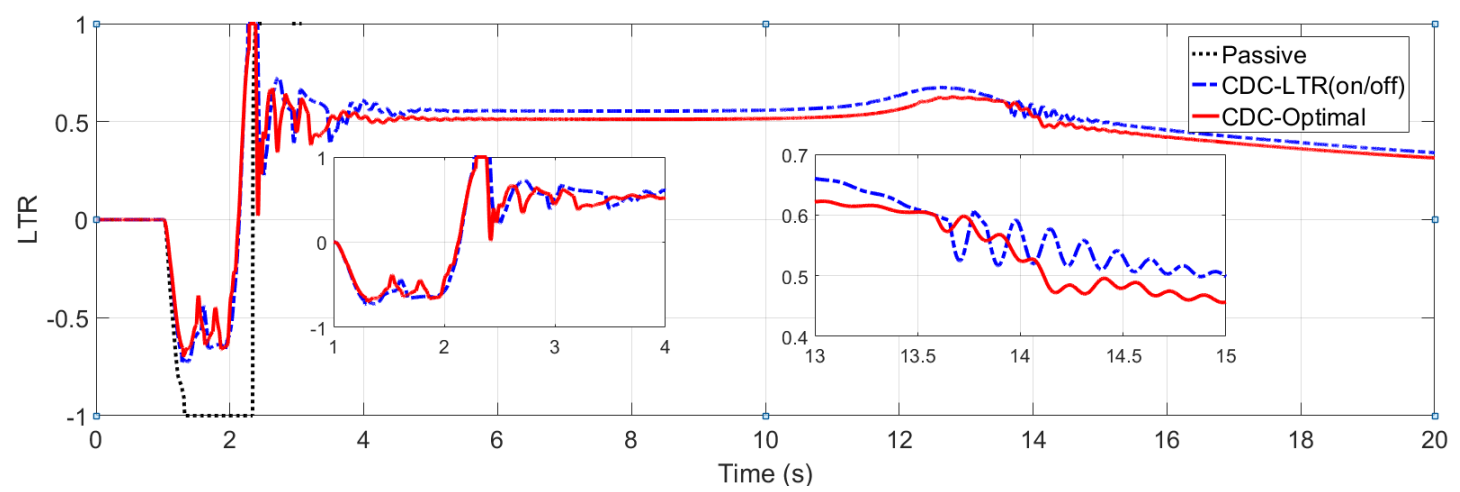

(c)

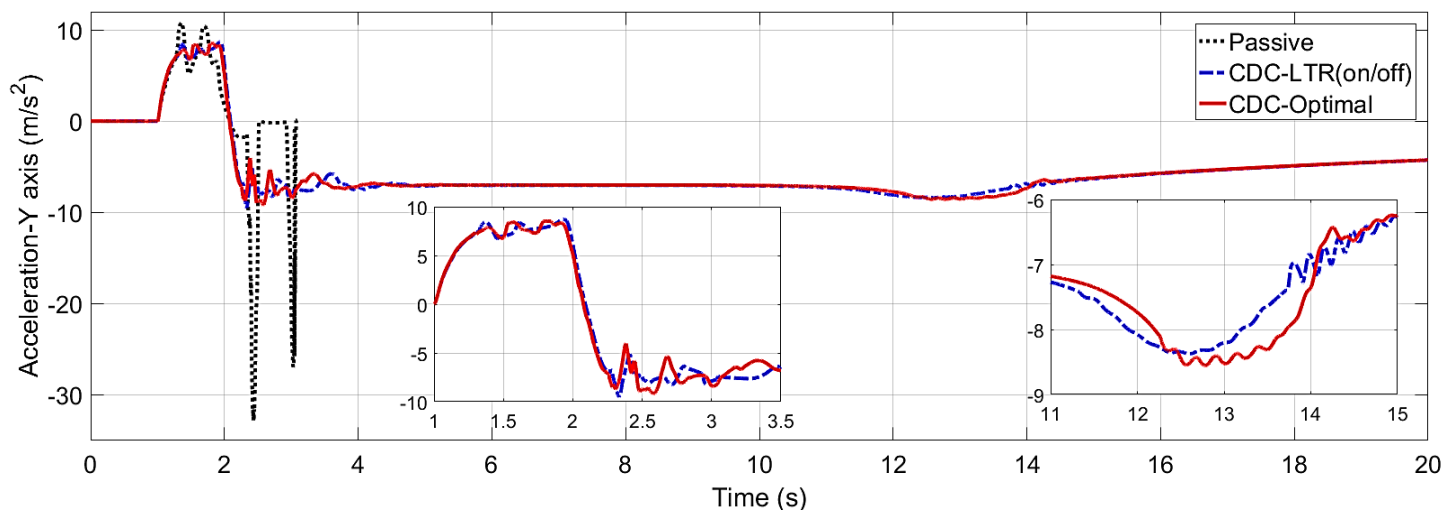

(d)

Figure 7. Roll angle, roll angle rate, LTR, and lateral acceleration of fishhook test. The result of passive suspension is expressed by the black dotted line. The result of CDC-LTR is expressed by the blue chained line. The result of CDC- optimal distribution damping force (ODDF) is expressed by the red solid line. (a) is the comparison result of the roll angle. (b) is the comparison result of the roll angle rate. (c) is the comparison result of LTR. (d) is the comparison result of lateral acceleration. To observe the comparison of the two CDC control strategies more conveniently, a local view in which passive suspension is removed is added.

The results of the roll angle, roll velocity, and LTR of these three modes show that both CDC control methods can effectively prevent rollover.

The result of the roll angle demonstrates that the roll angle rate of the vehicle with passive suspension reaches $-6 \mathrm{rad} / \mathrm{s}$ in approximately $3 \mathrm{~s}$, and the roll angle exceeds the limit, thus causing serious rollover. From the result of LTR, the vehicle with passive suspension reaches the rollover threshold at the first turning left in $1 \mathrm{~s}$. Given the influence of some factors, such as sideslip and small inertia, the vehicle is in an unstable state without rollover. However, after the 1.57 th second of continuous right turning, the vehicle can no longer maintain driving. Finally, at approximately the 2.2 th second, LTR jumps directly from -1 to +1 , indicating that rollover occurs. At approximately the 3rd second, the parameter has no significance. However, some LTR values with a discontinuous value of +1 still remain.

Comparing the CDC-ODDF control with the CDC-LTR control, the overall parameter performance of the vehicle seems to have little difference. However, it is determined by the rollover critical condition. LTR also reaches +1 from the 2.1th second to the 2.2th second under these two control strategies. The rollover cannot happen because the vehicle is in a critical unstable state.

This result can be compared through the vertical and damping forces in Figure 8. 


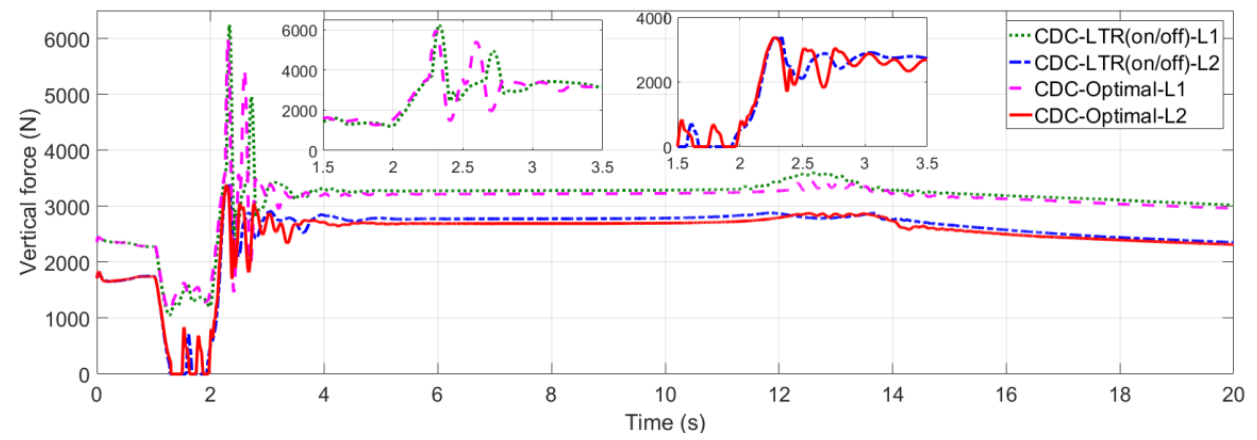

(a)

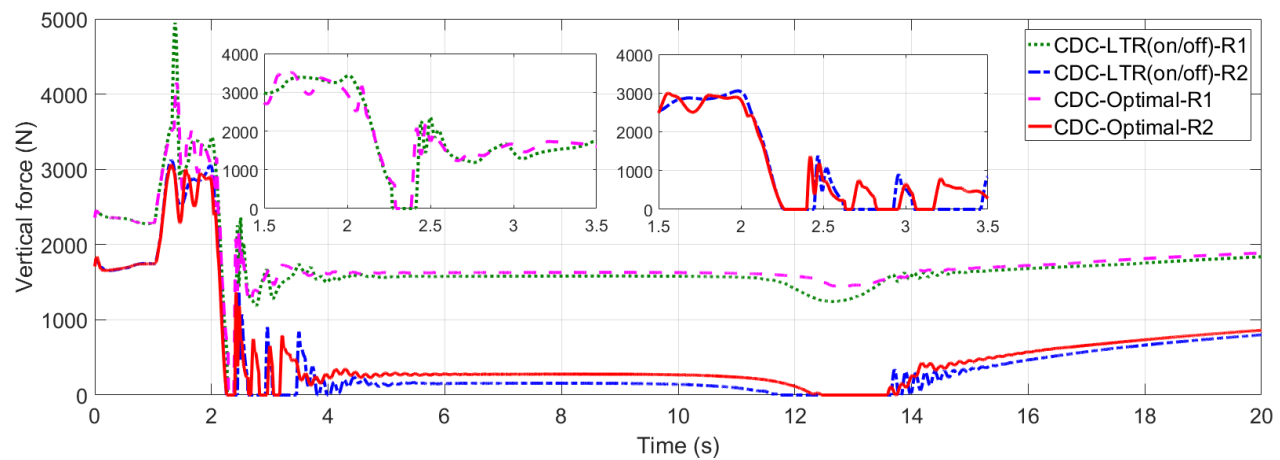

(b)

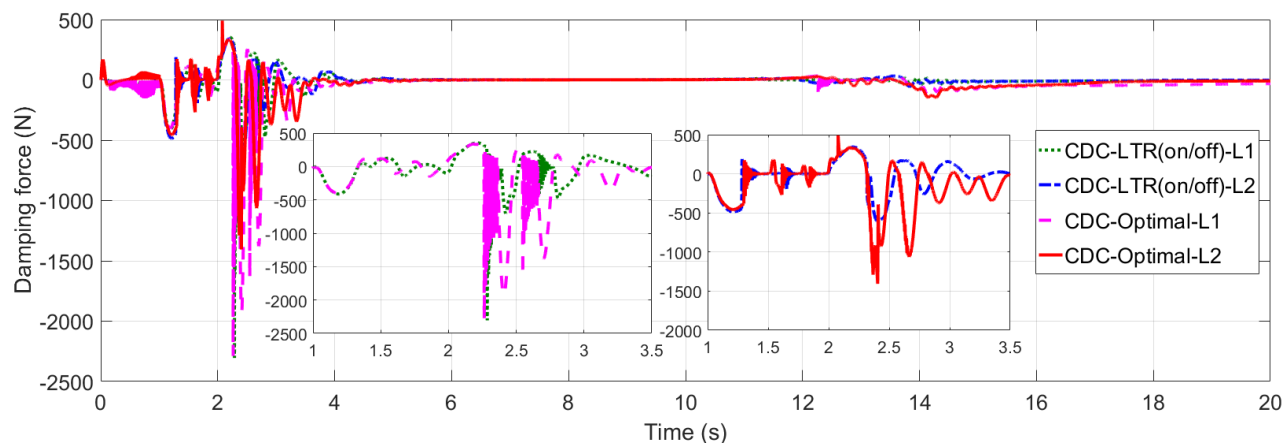

(c)

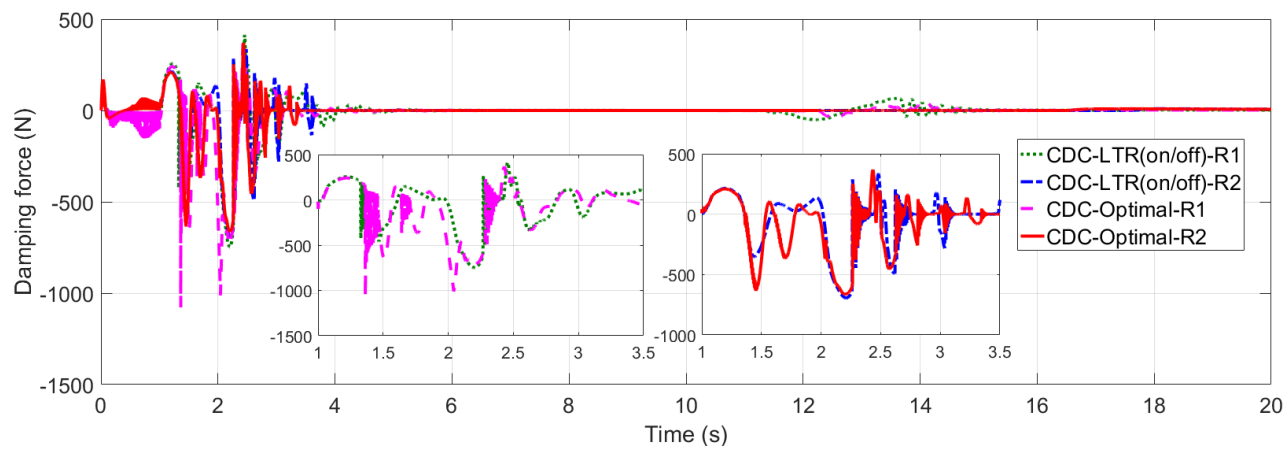

(d)

Figure 8. Vertical and damping forces of each wheel in fishhook test with CDC-LTR and CDC-ODDF. The details can be seen in the legend. (a) is the comparison result of the vertical forces of wheels on the left. (b) is the comparison result of the vertical forces of wheels on the right. (c) is the comparison result of the damping forces of wheels on the left. (d) is the comparison result of the damping forces of wheels on the right. $\mathrm{L}$ is short for left, and $\mathrm{R}$ is short for right. Here, 1 represents the front axle, and 2 denotes the rear axle. 
The comparison of the vertical forces demonstrates that the time during the wheel load on the same side at the same time is zero if the vehicle with CDC-ODDF is shorter. The vertical force of the right wheel of the rear axle is evidently reduced from the 1.6th second to the 1.8th second with CDC-ODDF. The vertical force of the left wheel of the front axle also decreases to a certain extent from the 2.3th second to the 2.4th second with CDC-ODDF. It can decrease the load transfer during roll, which is also the reason why the LTR value is less than CDC-LTR control.

Moreover, the advantages of CDC-ODDF can be determined by comparing the damping forces, which is the core part of the CDC-ODDF. The comparison of Figure $8 c, d$ shows that when the left side needs a very large damping force, the right side of the vehicle with CDC-ODDF also increases correspondingly. The critical state of rollover from the 1st second to the 3.5th second is taken for analysis, and the corresponding local enlarged contrast view is shown in Figure 8. In the interval of the 1.4th second to the 1.6th second, the maximum forward steering wheel condition is reached. The roll angle rate fluctuates at approximately the 1.4th second. To ensure the stable driving of the vehicle, the damping forces on the right side of the vehicle with CDC-ODDF achieve the first peak to compensate for the small damping force on the left side. At the same time, the damping forces on the right side with CDC-LTR are only approximately half of the forces with CDC-ODDF because LTR is very small, and CDC-LTR control is in the off state. When the steering system starts to turn right at approximately the 1.57th second, the damping forces with CDC-ODDF react immediately, while the CDC-LTR cannot respond in time and the output of damping force is still very small. At the peak value of LTR at approximately the 2.3th second, the compensation effect with CDC-ODDF is more evident. During this period, the damping forces with CDC-ODDF on the right side of the front axle compensate for the left side once at approximately the 2nd second, while the left side has several large compensations for the right side from the 2.4th second to the 2.6th second. The compensation of the left side of the rear axle and the right side of the front axle is the most evident from the data of the view with CDC-ODDF. Because the damping forces of CDC are controlled by electrical signal, the sudden changes of damping forces often lead to the sudden change of control current. The damping force current signal can be collected and identified by appropriate methods, and the driver can be given a corresponding real-time rollover warning, which improves the rollover prediction effect.

The main comparison results of CDC-LTR and CDC-ODDF are shown in Table 4.

Table 4. Main comparison results of fishhook test (CDC-LTR, CDC-ODDF).

\begin{tabular}{ccccc}
\hline \multicolumn{2}{c}{ Test Results (Unit) } & CDC-LTR & CDC-ODDF & Percentage Point ${ }^{\mathbf{1}}$ \\
\hline \multirow{2}{*}{ Roll angle $(\mathrm{rad})$} & maximum & 0.008001 & 0.07378 & $-7.79 \%$ \\
& minimum & -0.09906 & -0.09281 & $-6.30 \%$ \\
& average & -0.04896 & -0.04605 & $-5.94 \%$ \\
& standard deviation & 0.03012 & 0.02856 & $-5.18 \%$ \\
\hline \multirow{2}{*}{ Roll angle rate $(\mathrm{rad} / \mathrm{s})$} & maximum & 0.5657 & 0.4664 & $-5.34 \%$ \\
& minimum & -0.8282 & -0.7776 & $-6.11 \%$ \\
& average & -0.02054 & -0.01906 & $-7.21 \%$ \\
& standard deviation & 0.09313 & 0.08186 & $-12.1 \%$ \\
\hline
\end{tabular}

${ }^{1}$ Percentage point $=(($ CDC-ODDF $)-($ CDC-LTR $)) /($ CDC-LTR $) \times 100 \%$.

\subsection{Crosswind Test}

The crosswind test is important because crosswind is the most common lateral force, except for obstacles on the road, in practical application scenarios [43]. The general wind scale is the wind speed at $10 \mathrm{~m}$ above the ground, which prevents a higher wind speed on the ground. However, many overpasses are applied to urban expressways in the construction of modern cities. Sometimes, the height of these overpasses can even reach the height of $20 \mathrm{~m}$ from the ground (equivalent to approximately seven floors). The crosswind at this location is very dangerous to fast vehicles with a large mass and a high mass center on rainy and snowy days. The research condition of crosswind rollover is not only the condition of single lateral external force but also has a certain reference value 
in practical application. The basic parameters of the crosswind test simulation analysis are shown in Table 5.

Table 5. Main parameters of crosswind test.

\begin{tabular}{ccc}
\hline Test Parameters & Value & Unit \\
\hline Longitude target speed & 80 & $\mathrm{~km} / \mathrm{h}$ \\
Friction coefficient (no crosswind) & 0.85 & - \\
Friction coefficient (crosswind) & 0.2 & - \\
Wind speed & 8 & $\mathrm{~m} / \mathrm{s}$ \\
Simulation time & 8 & $\mathrm{~second}$ \\
Road condition & straight & - \\
|Threshold of CDC-LTR control| & 0.9 & - \\
\hline
\end{tabular}

Crosswind conditions are more severe because the friction coefficient of the crosswind section is small. Thus, serious instability sideslip occurs before a rollover. Therefore, these factors are combined with the test results for a brief analysis.

The results of crosswind test simulation are shown in Figure 9.

According to the results of the roll angle rate and LTR, the vehicle suffers from the first low-friction crosswind section from the 0.8 th second to the 2 nd second, enters the second friction crosswind section from the 3.5th second to the 4.2th second, and the vehicles start to lose stability from the 5.2th second to the 5.5th second (the condition is mainly sideslip; some wheels are off the ground, but no rollover occurs). The serious sideslip occurs after the 7.2th second, and the vehicles can no longer maintain normal driving.

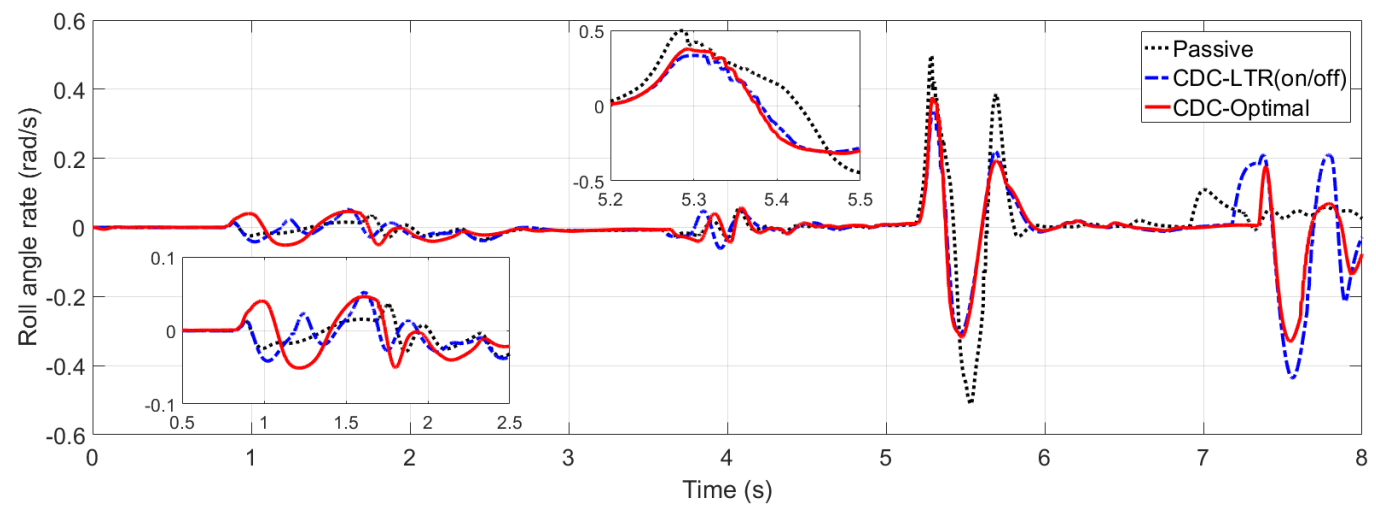

(a)

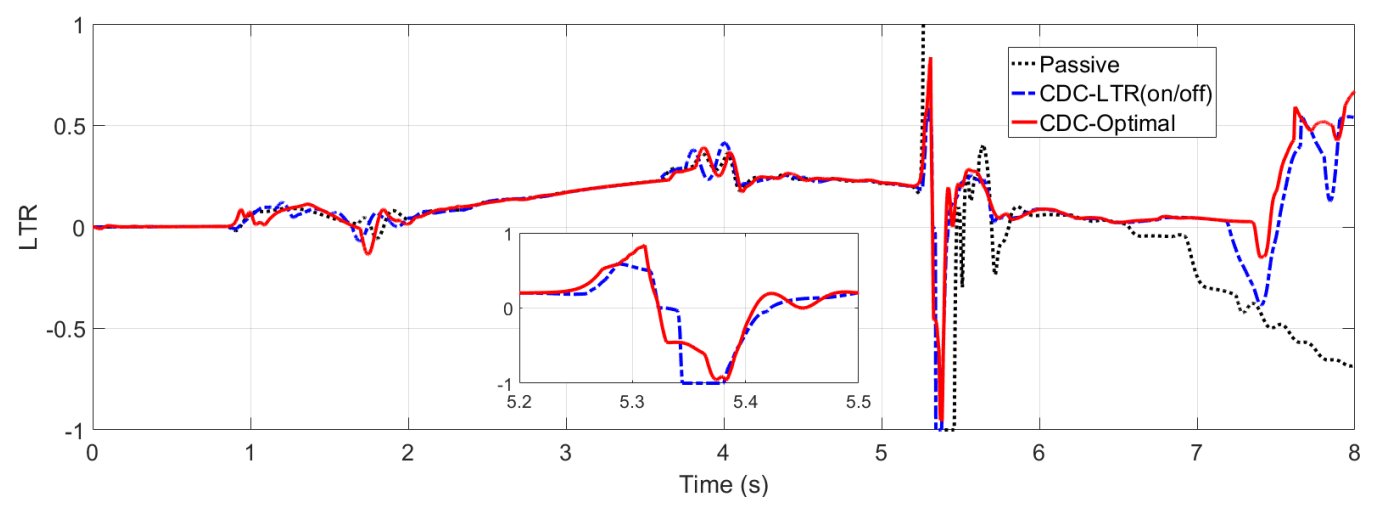

(b)

Figure 9. Cont. 


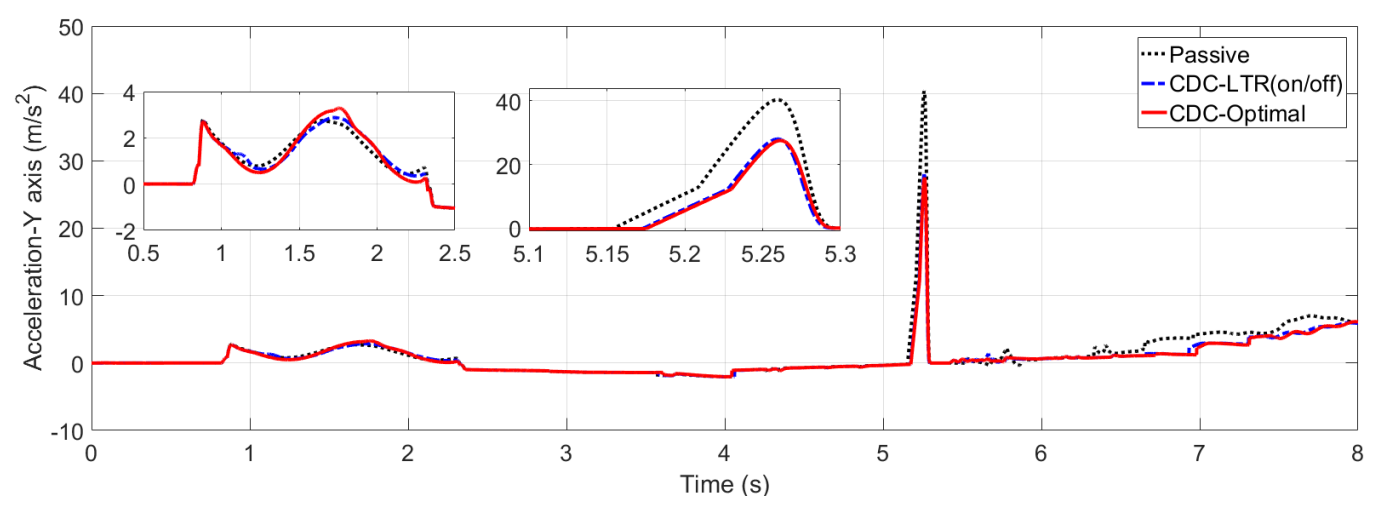

(c)

Figure 9. Roll angle rate, LTR, and lateral acceleration of crosswind test. The result of passive suspension is expressed by the black dotted line. The result of CDC-LTR is expressed by the blue chained line. The result of CDC-ODDF is expressed with the red solid line. (a) is the comparison result of the roll angle rate. (b) is the comparison result of LTR. (c) is the comparison result of lateral acceleration. To observe the comparison of the two CDC control strategies more conveniently, a local view, in which the passive suspension is removed, is added.

The LTR of a passive suspension vehicle experiences a jump from +1 to -1 at approximately the 5.2th second, which means that the vehicle has a "jump" on all wheels. Although no rollover occurs, the vehicle completely loses control. The vehicle with CDC is also unstable. Nevertheless, not all the wheels come off the ground. Notably, a vehicle with CDC-ODDF never reaches the rollover limit (|LTR| $<1$ from start to the end).

Moreover, the comparison of CDC-LTR and CDC-ODDF in two crosswind regions with low friction and the first instability region is analyzed on the basis of vertical and damping forces in Figure 10.

In the first crosswind section (from the 0.8th second to the 2nd second), the change of damping forces on the left side with the two CDC control strategies is basically the same, while the damping forces on the right side is evidently compensated for the left side with CDC-ODDF. Similarly, the adjustment of the vehicle with CDC-ODDF is faster and more sensitive than that with CDC-LTR. In the second crosswind section (from the 3.5th second to the 4.2th second), the compensation of the left damping force with CDC-ODDF is also evident (especially on the left side of the rear axle). This effect is more prominent at the first instability period. At approximately the 5.28th second, the right damping forces of the vehicle with CDC-ODDF has a compensation effect on the left side. This compensation effect eventually leads to the axle load transfer without exceeding the rollover threshold. Although the vehicle with CDC-ODDF still loses stability in the end, the smaller axle load transfer brings a better contact effect between the tires and the road surface. This result can also be seen from the comparison of vertical forces. Under the extreme instability condition at approximately the 3.35th second, the CDC-ODDF control can ensure that the two tires of the vehicle touch the ground, while CDC-LTR, which only has the wheel on the right side of the rear axle, has vertical force.

Although the effect of lateral force on the roll control is not evident (caused by sideslip), the CDC suspension still has great advantages compared with passive suspension. The strategy of CDC-ODDF is better than CDC-LTR. The optimal control strategy is adopted is not only to control the rollover, but also to change the distribution of damping forces and even the vertical forces of the vehicle. In addition, the redistribution of vertical forces can be combined with vehicle ESC control to achieve the goal of assisting ESC lateral stability control. Meanwhile, CDC plays an important role in driving stability with auxiliary effects. 


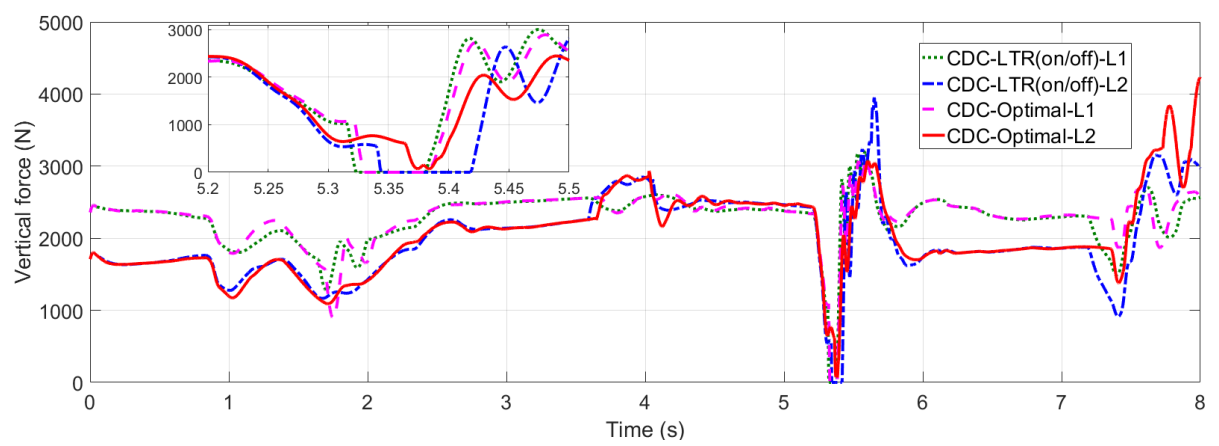

(a)

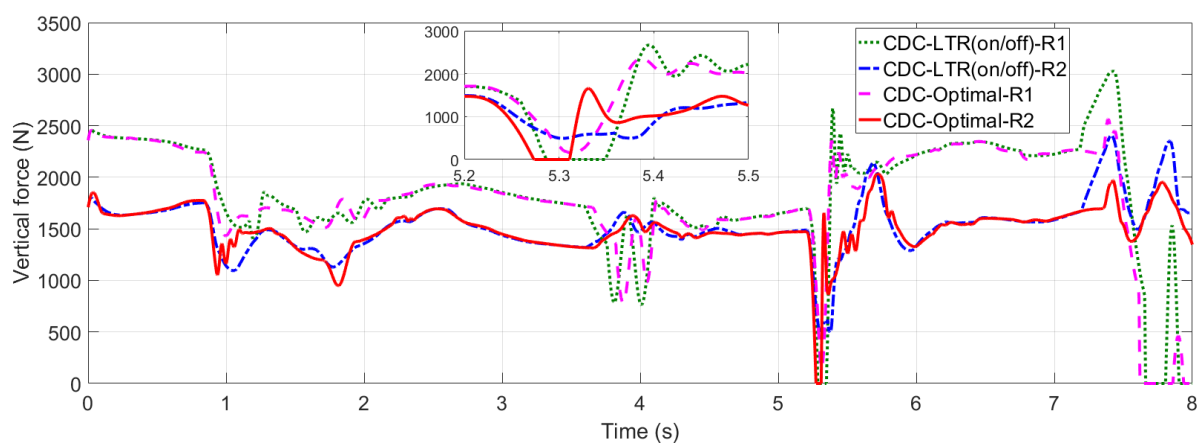

(b)

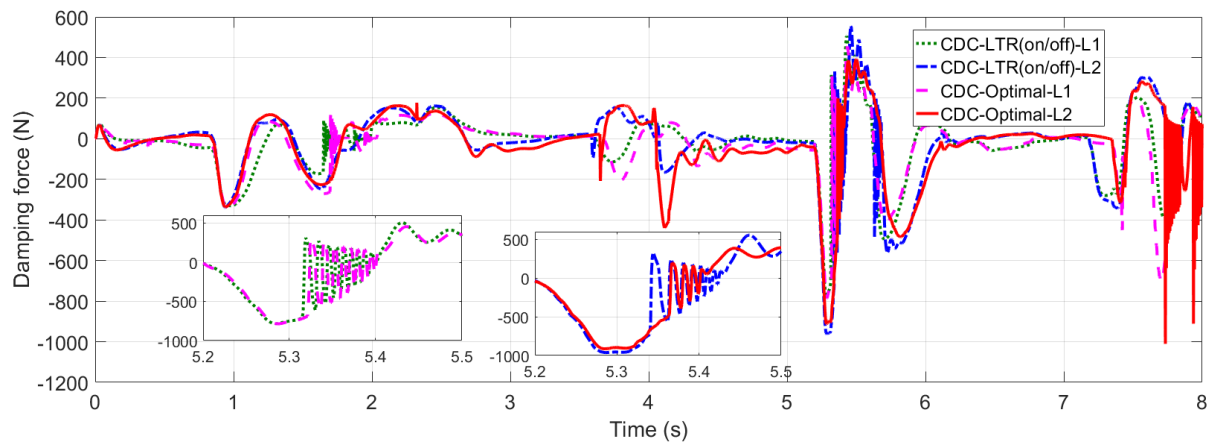

(c)

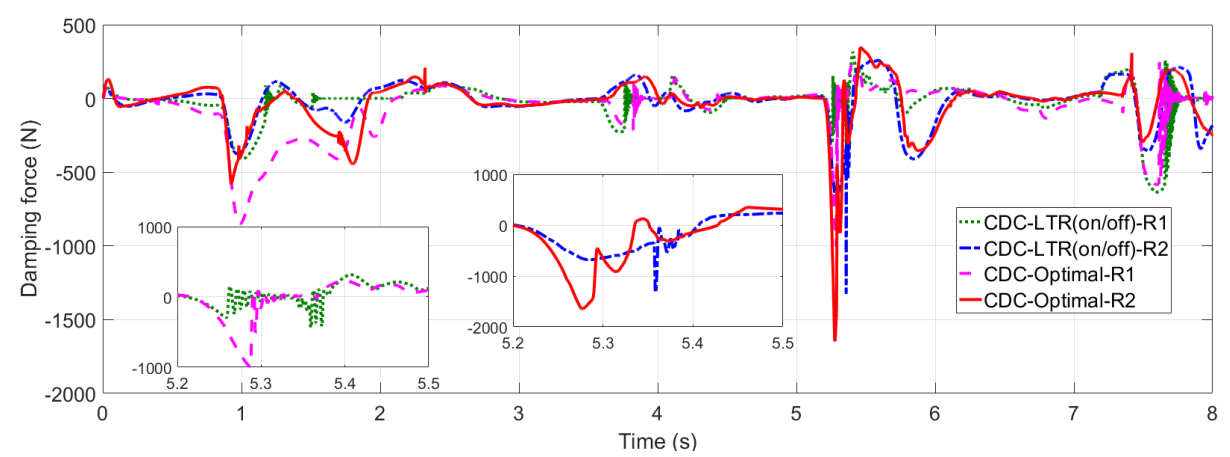

(d)

Figure 10. Vertical and damping forces of each wheel in crosswind test with CDC-LTR and CDC-ODDF. The details can be seen in the legend. (a) is the comparison result of the vertical forces of wheels on the left. (b) is the comparison result of the vertical forces of wheels on the right. (c) is the comparison result of the damping forces of wheels on the left. (d) is the comparison result of the damping forces of wheels on the right. $\mathrm{L}$ is short for left, and $\mathrm{R}$ is short for right. 1 represents the front axle, and 2 denotes the rear axle. 


\section{Conclusions}

Vehicle rollover is an instantaneous process. Once the rollover threshold is reached, the actual rollover event is very close. CDC-ODDF can adjust the damping force of the suspension by calculating the best damping force in real time. Through the simulation analysis, CDC-ODDF achieves the same control effect as CDC-LTR, which is to effectively prevent rollover. We can find that the vehicle with CDC-ODDF has advantages in statistics, such as maximum value, minimum value, average value, and standard deviation, even under extreme conditions compared with CDC-LTR. In a certain degree, the key parameters are optimized, which shows good performance with CDC-ODDF. The optimal control strategy is adopted is not only to control the rollover but also to change the distribution of damping forces and even the vertical forces of the vehicle. In addition, the redistribution of vertical forces can be combined with vehicle ESC control to achieve the goal of assisting ESC lateral stability control.

The damping forces on the left and right sides with CDC-ODDF can automatically compensate each other to hinder or prevent the occurrence of a rollover trend. Thus, this kind of compensation function embodies the biggest design advantage of CDC-ODDF. The damping forces with CDC-ODDF can be adjusted adaptively to prevent roll motion because such an event can be calculated with the lateral force and roll moment. Because the damping forces of CDC are controlled by an electrical signal, the sudden changes of damping forces often lead to the sudden change of control current. The damping force current signal can be collected and identified by appropriate methods, and the driver can be given a corresponding real-time rollover warning, which improves the rollover prediction effect. In practical application, the damping force of suspension can be adjusted by CDC-ODDF to prevent rollover. In fact, by further designing the optimization target, the damping force distribution of the front and rear axles can be adjusted in real time, and the pitch during braking or other motions can be taken into account, so that the passengers can experience a better feeling.

Author Contributions: X.Z. conceived the control method, completed the modeling, performed simulation experiments, analyzed the results, and finished the manuscript. C.S. provided overall guidance for the study and managed the project. S.S. and F.X. collected the data and reviewed and revised the paper. J.C. gave crucial suggestions about the 14-degree-of-freedom model and participated in model verification. D.W. gave crucial suggestions about the LTR and optimal damping force control strategy. C.Q. and Z.M. put forward the idea and debugged the model in MATLAB/Simulink. All authors have read and agreed to the published version of the manuscript.

Funding: This research is supported by the Science and Technology Development Plan Program of Jilin Province (grant no. 20200401112GX), Industry Independent Innovation Ability Special Fund Project of Jilin Province (grant no. 2020C021-3).

Conflicts of Interest: The authors declare no conflict of interest.

\section{References}

1. Trends and Rollover-Reduction Effectiveness of Static Stability Factor in Passenger Vehicles. Available online: https://crashstats.nhtsa.dot.gov/Api/Public/ViewPublication/812444 (accessed on 7 April 2020).

2. Geospatial Summary of Crash Fatalities. Available online: https://crashstats.nhtsa.dot.gov/Api/Public/ ViewPublication/812607 (accessed on 28 August 2020).

3. Yim, S.; Park, Y. Design of rollover prevention controller with linear matrix inequality based trajectory sensitivity minimization. Veh. Syst. Dyn. 2011, 49, 1225-1244. [CrossRef]

4. Han, I.; Rho, K. Characteristic analysis of vehicle rollover accidents: Rollover scenarios and prediction/warning. Int. J. Automot. Technol. 2017, 18, 451-461. [CrossRef]

5. Chu, D.; Lu, X.-Y.; Wu, C.; Hu, Z.; Zhong, M. Smooth Sliding Mode Control for Vehicle Rollover Prevention Using Active Antiroll Suspension. Math. Probl. Eng. 2015, 2015, 478071. [CrossRef]

6. Wang, D.; Liu, L.; Hao, Y.; Li, H.; Tang, H. Simulation for structure Optimization design on truck rollover test. In Proceedings of the 2011 Second International Conference on Mechanic Automation and Control Engineering, Hohhot, China, 15-17 July 2011; Volume 6, pp. 671-674. [CrossRef]

7. Winkler, C.; Ervin, D. Rollover of heavy commercial vehicles. UMTRI Res. Rev. 2000, 31, 1-17. 
8. Huston, R.L.; Kelly, F.A. Another look at the static stability factor (SSF) in predicting vehicle rollover. Int. J. Crashworthiness 2014, 19, 567-575. [CrossRef]

9. Johansson, B.; Gafvert, M. Untripped SUV rollover detection and prevention. In Proceedings of the 2004 43rd IEEE Conference on Decision and Control (CDC) (IEEE Cat. No.04CH37601), Nassau, Bahamas, 14-17 December 2004; Volume 5, pp. 5461-5466.

10. Goldman, R.; El-Gindy, M.; Kulakowski, B. Rollover dynamics of road vehicles: Literature survey. Int. J. Heavy Veh. Syst. 2001, 8, 103. [CrossRef]

11. Rajamani, R.; Piyabongkarn, D.; Tsourapas, V.; Lew, J. Real-time estimation of roll angle and CG height for active rollover prevention applications. In Proceedings of the 2009 American Control Conference, St. Louis, MO, USA, 10-12 June 2009; pp. 433-438.

12. Imine, H.; Benallegue, A.; Madani, T.; Srairi, S. Rollover Risk Prediction of Heavy Vehicle Using High-Order Sliding-Mode Observer: Experimental Results. IEEE Trans. Veh. Technol. 2013, 63, 2533-2543. [CrossRef]

13. Rath, J.; Defoort, M.; Veluvolu, K.C. Rollover Index Estimation in the Presence of Sensor Faults, Unknown Inputs, and Uncertainties. IEEE Trans. Intell. Transp. Syst. 2016, 17, 2949-2959. [CrossRef]

14. Zhang, X.; Yang, Y.; Guo, K.; Lv, J.; Peng, T. Contour line of load transfer ratio for vehicle rollover prediction. Veh. Syst. Dyn. 2017, 55, 1748-1763. [CrossRef]

15. Phanomchoeng, G.; Rajamani, R. Real-Time Estimation of Rollover Index for Tripped Rollovers with a Novel Unknown Input Nonlinear Observer. IEEE/ASME Trans. Mechatron. 2013, 19, 743-754. [CrossRef]

16. Larish, C.; Piyabongkarn, D.; Tsourapas, V.; Rajamani, R. A New Predictive Lateral Load Transfer Ratio for Rollover Prevention Systems. IEEE Trans. Veh. Technol. 2013, 62, 2928-2936. [CrossRef]

17. Yoon, J.; Kim, N.; Yi, K. Design of a rollover index-based vehicle stability control scheme. Veh. Syst. Dyn. 2007, 45, 459-475. [CrossRef]

18. Ju-Long, D. Control problems of grey systems. Syst. Control Lett. 1982, 1, 288-294. [CrossRef]

19. Chou, T.; Chu, T.-W. An improvement in rollover detection of articulated vehicles using the grey system theory. Veh. Syst. Dyn. 2014, 52, 679-703. [CrossRef]

20. Mashadi, B.; Mostaghimi, H. Vehicle lift-off modelling and a new rollover detection criterion. Veh. Syst. Dyn. 2017, 55, 704-724. [CrossRef]

21. Chen, B.-C.; Peng, H. Differential-Braking-Based Rollover Prevention for Sport Utility Vehicles with Human-in-the-loop Evaluations. Veh. Syst. Dyn. 2001, 36, 359-389. [CrossRef]

22. Dahmani, H.; Chadli, M.; Rabhi, A.; El Hajjaji, A. Vehicle dynamic estimation with road bank angle consideration for rollover detection: Theoretical and experimental studies. Veh. Syst. Dyn. 2013, 51, 1853-1871. [CrossRef]

23. Stankiewicz, P.G.; Brown, A.A.; Brennan, S.N. Preview Horizon Analysis for Vehicle Rollover Prevention Using the Zero-Moment Point. J. Dyn. Syst. Meas. Control 2015, 137, 091002. [CrossRef]

24. Ataei, M.; Khajepour, A.; Jeon, S. A general rollover index for tripped and untripped rollovers on flat and sloped roads. Proc. Inst. Mech. Eng. Part D J. Automob. Eng. 2019, 233, 304-316. [CrossRef]

25. Shim, T.; Ghike, C. Understanding the limitations of different vehicle models for roll dynamics studies. Veh. Syst. Dyn. 2007, 45, 191-216. [CrossRef]

26. Yim, S.; Jeon, K.; Yi, K. An investigation into vehicle rollover prevention by coordinated control of active anti-roll bar and electronic stability program. Int. J. Control Autom. Syst. 2012, 10, 275-287. [CrossRef]

27. Yim, S.; Lim, C.W.; Oh, M.-H. An investigation into the structures of linear quadratic controllers for vehicle rollover prevention. Proc. Inst. Mech. Eng. Part D J. Automob. Eng. 2012, 227, 472-480. [CrossRef]

28. Yim, S. Design of a rollover prevention controller with differential game theory and a coevolutionary genetic algorithm. J. Mech. Sci. Technol. 2011, 25, 1565-1571. [CrossRef]

29. Muniandy, V.; Samin, P.; Jamaluddin, H. Application of a self-tuning fuzzy PI-PD controller in an active anti-roll bar system for a passenger car. Veh. Syst. Dyn. 2015, 53, 1641-1666. [CrossRef]

30. Solmaz, S.; Shorten, R.; Wulff, K.; Cairbre, F.Ó. A design methodology for switched discrete time linear systems with applications to automotive roll dynamics control. Automatica 2008, 44, 2358-2363. [CrossRef]

31. Van Der Westhuizen, S.F.; Els, P.S. Slow active suspension control for rollover prevention. J. Terramechanics 2013, 50, 29-36. [CrossRef]

32. Yoon, J.; Cho, W.; Koo, B.; Yi, K. Unified Chassis Control for Rollover Prevention and Lateral Stability. IEEE Trans. Veh. Technol. 2008, 58, 596-609. [CrossRef] 
33. Yoon, J.; Cho, W.; Kang, J.; Koo, B.; Yi, K. Design and evaluation of a unified chassis control system for rollover prevention and vehicle stability improvement on a virtual test track. Control Eng. Pr. 2010, 18, 585-597. [CrossRef]

34. Tchamna, R.; Youn, E.; Youn, I. Combined control effects of brake and active suspension control on the global safety of a full-car nonlinear model. Veh. Syst. Dyn. 2014, 52, 69-91. [CrossRef]

35. Tarko, A.P.; Hall, T.; Romero, M.; Jiménez, C.G.L. Evaluating the rollover propensity of trucks-A roundabout example. Accid. Anal. Prev. 2016, 91, 127-134. [CrossRef]

36. Zhu, B.; Piao, Q.; Zhao, J.; Guo, L. Integrated chassis control for vehicle rollover prevention with neural network time-to-rollover warning metrics. Adv. Mech. Eng. 2016, 8, 1-13. [CrossRef]

37. Bencatel, R.; Tian, R.; Girard, A.; Kolmanovsky, I. Reference Governor Strategies for Vehicle Rollover Avoidance. IEEE Trans. Control Syst. Technol. 2017, 26, 1954-1969. [CrossRef]

38. Zhao, J.; Wong, P.K.; Ma, X.; Xie, Z. Chassis integrated control for active suspension, active front steering and direct yaw moment systems using hierarchical strategy. Veh. Syst. Dyn. 2016, 55, 72-103. [CrossRef]

39. Zhao, W.; Ji, L.; Wang, C. Ho control of anti-rollover strategy based on predictive vertical tire force. Trans. Inst. Meas. Control 2017, 40, 3587-3603. [CrossRef]

40. Luo, Y.; Cao, K.; Dai, Y.; Chu, W.; Li, K. A Novel Hierarchical Global Chassis Control System for Distributed Electric Vehicles. SAE Int. J. Passeng. Cars Electron. Electr. Syst. 2014, 7, 313-327. [CrossRef]

41. Cao, K.; Luo, Y.; Dai, Y.; Chu, W.; Chen, L.; Li, K. Collaborative Control of Longitudinal/Lateral/Vertical Tire Forces for Distributed Electric Vehicles. Automot. Eng. 2015, 37, 985-991.

42. Ataei, M.; Khajepour, A.; Jeon, S. Rollover stabilities of three-wheeled vehicles including road configuration effects. Proc. Inst. Mech. Eng. Part D J. Automob. Eng. 2017, 231, 859-871. [CrossRef]

43. Giappino, S.; Rocchi, D.; Schito, P.; Tomasini, G. Cross wind and rollover risk on lightweight railway vehicles. J. Wind. Eng. Ind. Aerodyn. 2016, 153, 106-112. [CrossRef]

Publisher's Note: MDPI stays neutral with regard to jurisdictional claims in published maps and institutional affiliations.

(C) 2020 by the authors. Licensee MDPI, Basel, Switzerland. This article is an open access article distributed under the terms and conditions of the Creative Commons Attribution (CC BY) license (http://creativecommons.org/licenses/by/4.0/). 